Review

\title{
News in Bone Modeling for Customized Hybrid Biological Prostheses Development
}

\author{
${ }^{1}$ Relly Victoria Virgil Petrescu, ${ }^{2}$ Raffaella Aversa, ${ }^{2}$ Valeria Perrotta, \\ ${ }^{1}$ Liviu Marian Ungureanu, ${ }^{2}$ Antonio Apicella and ${ }^{1}$ Florian Ion Tiberiu Petrescu \\ ${ }^{1}$ IFToMM, ARoTMM, Bucharest Polytechnic University, Bucharest, Romania \\ ${ }^{2}$ Advanced Materials Lab, Department of Architecture and Industrial Design, Second University of Naples, Aversa, Italy
}

\author{
Article history \\ Received: 23-01-2021 \\ Revised: 19-04-2021 \\ Accepted: 28-05-2021 \\ Corresponding Author: \\ Florian Ion Tiberiu Petrescu \\ IFToMM, ARoTMM, \\ Bucharest Polytechnic \\ University, Bucharest, \\ Romania \\ Email: tiberiuflorianion@gmail.com
}

\begin{abstract}
The complex biomechanics and morphologies of the femur proximal epiphysis are presented. The nature and fine morphology of the femur head and its structural behavior have been investigated. Isotropic and orthotropic trabecular structures have been associated with oriented compression and tensioned areas of the femur head FEM models. These isotropic/orthotropic trabecular morphologies and their allocations govern the stress and strain distribution in the overall proximal femur region. Finite element models of the femur biofidel were developed using a specific combination of segmentation with computed tomography and solid modeling tools capable of representing bone physiology and structural behavior. This biofidel Finite Element (FEM) model is used to evaluate the change in the physiological distribution of stress in the femoral prosthesis and to evaluate the new design criteria for biopsy. The use of femur proper biofidel modeling while enabling the explanation of physiological stress distribution elucidates the critical mechanical role of the trabecular bone that should be accounted for in the design new innovative more "biologic" prosthetic system. Biomimetics, biomechanics and tissue engineering are three multidisciplinary fields that have been considered in this research to achieve the goal of improving the reliability of prosthetic implants. The authors took these studies to gather the untapped potential of such advanced materials and design technologies by developing finite models of Biofidel elements capable of correctly mimicking the biomechanical behavior of the femur.
\end{abstract}

Keywords: Trabecular Bone, Biomimetic, Biomaterials, Biomechanics, Femur, Prostheses, Bioengineering

\section{Introduction}

The body of an adult has 206 bones and a complex network of tendons, ligaments and cartilage that supports it. It has a number of vital functions, such as supporting, moving, protecting, producing red blood cells, storing calcium and balancing the endocrine system. In other words, without him, we would not be able to live.

The number of bones a man is born with is not the final one. Humans are born with about 300 bones, some of which fuse as the body develops. Males develop fully by the end of adolescence and females up to two years after the beginning of the menstrual cycle.

The skeletal system differs between men and women, mainly in the shape of the pelvis: In women, it must support pregnancy.
Although they become rigid and fragile outside the body, inside it is of course living tissue and the strength is different. It is fed by a network of blood cells from the circular system and nerves from the nervous system.

The bones have a hard, dense outer shell. Then comes the spongy bone, which is lighter and more flexible. Inside, in some bones, is the spinal cord, where new cells are constantly produced.

Teeth are considered to be part of the skeletal system, but they are not considered bones. They are made of dentin and enamel, the most resistant substances in the body.

The skeletal system has two major components: The axial skeleton and the appendicular skeleton. The axial one has 80 bones, being made up of the spine, the thoracic box and the skull. The appendicular has a total 
of 126 bones and consists of the rest, such as the limbs and pelvis.

The main tools for diagnosing diseases are those that can see beyond the soft tissue, such as the skin and organs. With the help of MRI, arthroscopy and radiographs, accurate diagnoses can be made, such as deformities or cancer.

The most common diseases are metabolic diseases, such as osteoporosis. It occurs mainly in the elderly and is manifested by loss of bone tissue. In other words, the bones lose calcium, become lighter, or even disappear. Osteomalacia, another common disease, is manifested by loss of bone hardness, resulting from vitamin $\mathrm{D}$ deficiency.

Arthritis is a group of over 100 inflammatory diseases that affect the joints and structures around them. It usually affects the most requested joints, such as the shoulders, knees, lumbar region, hips and carpels.

Scoliosis is also a common condition, which means bending in one part of the spine. The condition usually occurs in adolescence. In the United States alone, 2-3\% of the population suffers from this disease.

One of the rare but extremely dangerous conditions is bone cancer. It can even come from the bones or it can appear in the skeletal tissue from another tumor that is spreading in the body. In 2018, an estimated 1,590 people will die of bone cancer in the United States alone. This type of cancer has an occurrence of only $0.2 \%$. "Unfortunately, today this type of cancer is found especially in young patients aged $20-30$ years."

Leukemia is also associated with the skeletal system. This condition, which can be said to be blood cancer, has its origin in the bone marrow. Here, white blood cells multiply at an uncontrolled rate. This may be due primarily to a strong acute infection, but also to other prolonged or genetic stressors.

Bursitis is a condition that usually affects the shoulder and hip joints. It is caused by inflammation and fluid filling of the tissue.

\section{The Bone System is also Susceptible to Fractures}

The bones retain many toxic substances $(\mathrm{Hg}, \mathrm{Pb}, \mathrm{F})$ that accidentally enter the body and release them gradually, being then eliminated by the kidneys. In this way, the blood concentration of the toxicant does not increase too much and harmful effects on other organs are prevented.

In children, all the bones and in adults, the wide bones contain red, haematogenous marrow. In adults, the marrow in the central canal of the diaphysis of the long bones is yellow (adipose tissue with a reserve role) and in the elderly, it is gray, almost non-functional.

Bones also play an essential role in the metabolism of calcium, phosphorus and electrolytes, maintaining physiological balance in the body. Bones are the main reservoir of mineral substances in the body.
The roles of the skeletal system in the human body are therefore extremely important. It must be understood from the start that the skeletal system is not just a shield to defend the internal organs and a skeleton to support these internal organs, which was difficult anyway being dynamic support while walking or running. The skeletal system is thought of as an organ with multiple roles in the human body. First of all, it is the one that produces and maintains all the basic cells of the body, including plasma. Blood is the body's vital fluid that carries food to the basic cells of the whole body constantly, along with energy, energy and nutrients, plus oxygen. He is also the one who returns the toxins from the basic cells of the body back to the organs that will throw them out of the body, the products eliminated by the cells from nutrition and oxygenation will be returned through the blood to the kidneys, liver, interstitial fluid, lungs, for processing and elimination. The blood also carries extremely important mineral salts to the cells of the whole body. All the blood is manufactured and regenerated permanently in the bones, in their bone marrow, mostly in the spinal cord and in the large, wide bones. In children, almost all the bones participate in this process, in adults they diminish and in the elderly, the bones that produce the bone marrow, which is responsible for the production of blood, the vital plasma for the body, almost disappear. Hence the first cause of aging of the human body, with the decrease in the number of bone makers of plasma, with age, which leads in time to insufficiency of a new plasma clean, oxygenated, nourished, energetic. The human bone marrow is also the one that produces a large number of red blood cells, erythrocytes, cells responsible for blood clotting in case of platelet injury and most white blood cells for the body's immune defense leukocytes, which are extremely diverse and very many categories and forms, today we know only a few of the existing types, otherwise, they are constantly diversifying and depending on the new defense needs of the body against new intruders who can also be more diverse, especially since the new virus strains.

Today the problem of new leukocytes that can fight effectively against new strains of mutant viruses is a serious even acute one, so we should all think of ways to get as much immunization as possible from the human body a natural dynamic, not through vaccinations, an enhanced immunity of the body through various classical procedures and procedures given and new, modern.

On the other hand, it must be thought that the bone marrow also produces the stem cells so desired and necessary by the human body because it adapts quickly to all areas of the body, to any organ, or part of it, helping to restore it when necessary after injuries, injuries, illnesses, i.e., when there is an acute crisis at a certain level of the body, except the brain, where the cells specialized in those areas cannot multiply quickly 
and well enough, stem cells adapt quickly to any area and properly restore the affected area in a timely manner, which helps a lot to keep the whole body young at the correct maintenance at almost any age, as long as the body has enough bone marrow, enough healthy bones to produce cells through their marrow plasma and the necessary stem cells. In addition, all will always be transported quickly to where they are needed due to the fresh plasma produced in sufficient quantities by the bone marrow of young, wide bones plus the spinal cord. Because of this, when the bones degrade from old age, disease, or injury, or due to an inadequate lifestyle, severe imbalances occur throughout the body that leads over time to disease, insufficiency, suffering, acute and then chronic, which not treated properly and in time will eventually lead to the death of the body.

We were talking about the fact that the skeletal system not only maintains and defends the internal organs but also has the role of producing plasma and its cells plus stem cells of vital importance for the whole body, but also the bones are those that have the essential role of creating a reserve of plasma, saline, nutrients, being at the same time a kind of thermos of the human body in which large reserves of vital fluids are stored, but also from those from which plasma is manufactured. So the bones keep the saltwater with the nutrients from which the plasma will also be made in them, but at the same time, they maintain a blood reserve, which can be pumped at any time with power and in sufficient quantities wherever it will be needed throughout the body. A reserve of blood is also made by the liver, lungs, kidneys, one of water, the interstitial fluid, but both saltwater with nutrients and freshly made blood are kept fresh even in the living thermos made by the very bones of the human body. For this reason, when there is great damage to the bones, for various reasons, there is a decrease in the supply of vital fluids, which leads to a decrease in the amount of useful plasma that can be produced and used and to possible disorders of the body. If the bones are not repaired in time they will affect in the long run or permanently the production of blood and its reserve in the body and the functioning of the whole body will become deficient and slowly the condition of the body will deteriorate and it will age. This will also result in the death of the body sooner or later.

Let us understand from here that the nutritional and respiratory processes of the whole organism depend directly and indirectly on the permanent amount of blood but also on the quality of the plasma at any moment, as well as on the body's basic reserve of the vital fluids, i.e., all these essential physiological processes are dependent, directly from the normal and healthy bone system. The rupture of an important bone will directly and immediately affect all these important processes and in the long run, the consequences can even become serious. Long-lasting bone disease or a serious injury to important bones or the spine could be even more devastating if this injury is not repaired properly and quickly. For this reason, this study tries to present various original methods to repair fractured bones correctly and in a timely manner, the paper representing a review of several efforts made in time in this field by its authors.

The energy processes inside each basic human cell are based on the energy of ATP-type molecular chains produced by the mitochondria in that cell. We remind you that mitochondria are practically minicells in cells that have various roles within the host cell, including control of feeding and energization, control of redox reduction, control of division for multiplication, selection of very sick, old, cancerous cells for the destruction process. Of mitochondria on standby or on the function of cells destined for their destruction, or self-destruction because they are too sick and can no longer heal and they are no longer allowed to divide so as not to give birth to inappropriate new cells. Within a human cell, there may be as many or as many mitochondrial cells as needed in that cell for more or less energy. For example, muscle cells, especially the heart, but also the neurons of the brain need more energy, so in the tissues of the muscles, heart and brain, there will be several mitochondria per cell, even 1000 mitochondria in a single human cell, in order to produce as many ATP-type molecular energy chains as donors of basic energy for the body, knowing that the extra energy obtained by the body from sugars, fats, etc., is not exactly clean and healthy.

Maybe here we should make a parenthesis, a clarification, that one of the essential organs, the human brain, its neuron, i.e., its basic cell, cannot be restored too easily and for a long time it was thought that the neurons initially in the huge reserve do not they can recover, but more recently it has been found that their reproduction time is very long, from 60 to 120 years, while other cells recover much faster. For example, the skin recovers completely in no more than 30 days, the ligament muscles recover completely in two to three weeks, the anal area recovers in just a few hours up to $24 \mathrm{~h}$ the eye cells can recover differentially from hours to weeks and so on.

It is not yet known exactly the mechanism by which the various cell types reproduce and how stem cells adapt anywhere, but it may be possible in the future to conduct studies and research to demonstrate the role of all factors that can help restore faster any area of the human body and even the brain, including stem cells.

Given the importance of the bone system as a whole and the fact that it is the one that controls the vitality of the whole body, the separate study of the various bones and how they can be repaired in case of injury with a 
fracture or even rupture, is very important because partial repair or blockage of the natural structure of the bones will lead in time to a bony area that will no longer give the necessary yield in storage and manufacture of vital fluids of the body and the affected area will degenerate and be damaged and the rest of the bones will difficult to be able to produce its part that it did before. From such degradations, the body can suffer a lot and over time there will be a malfunction, slow vital processes, incomplete, poor elimination of toxins from the body, with frequent poisoning and premature aging of the whole body.

An extremely interdisciplinary research group has been involved in the study of bone as a living material. The main efforts were dedicated to the imitation of bone characteristics and a process of its formations and behavior under physiological load (Apicella et al., 2010; 2011; Davide et al., 2015; Gramanzini et al., 2016; Kummer, 1986; Perillo et al., 2010; Sorrentino et al., 2009; 2007).

These investigations have led to advanced academic studies on the biomechanics and biomimetics of implanted bones. This study project identifies a number of design criteria to promote its potential to enable new medical therapies that contribute to personal health care and to create and improve the technological basis for innovative prosthesis design.

The human femur is characterized by a specific internal structure (Oh and Harris, 1978; Gottesman and Hashin, 1980) that gives the bone a great ability to withstand external stresses while optimizing its mass distribution and morphology (Ashman et al., 1984; Dalstra et al., 1993). However, the physiological loss of bone mass occurs progressively at an older age, reducing its resistance and ability to dissipate energy transmitted by external shock events and this feature is the cause of most pertrochanteric fractures of the elderly throughout the plan indicated in Fig. 1.

Aversa et al. (2016a) successfully modeled this behavior pertrochanteric fractures require the application of a hip joint prosthesis (Ashman and Rho, 1988; Burstein et al., 1976; Carter and Hayes, 1977).

The change in the biomechanical behavior of aged or implanted bones can be correctly predicted using Finite Element Modeling (FEM) of the previously developed biofidel. However, total hip replacement in patients under 65 years of age and therefore the required prolonged durability of the orthopedic implant may not last more than 15 years. However, this clinical scenario is changing now. Several technological developments in health have increased life expectancy. In addition, the prognosis of physical trauma caused by sports, excessive exercise and or road accidents has improved. The new design then requires durable and biomechanically compatible prostheses.
Orthopedic prostheses used today are made of metal alloys, plastics and ceramics with well-defined properties and characteristics. In particular, due to the biocompatibility of their high mechanical strength and commonly used metal alloys, they are based on cobalt, titanium, or chromium and represent almost all prosthetic components that are in direct contact with human bone, as they could provide optimal bones for integration.

Implant defects are mainly due to incompatibility between prosthesis and bone biomechanics, inadequate strength or rigidity, which is an inadequate bone for the implant, causing bone discontinuities in the distribution of stress and biological strains. Current implants (metal and ceramic) that are stiffer than bone, lead to physiological changes in the strong blood distribution and prevent the transfer of stress to the adjacent bone and weakening the implant (Apicella et al., 2010; 2011; Davide et al., 2015). To predict the structural changes induced by changes in bone morphological and mechanical characteristics, femoral models were developed (Aversa et al., 2016a). The development of these bio-models has already allowed us to strictly predict physiological stress and strain distribution in mandibular and prosthetic implants (Apicella et al., 2010; Gramanzini et al., 2016; Perillo et al., 2010; Sorrentino et al., 2009; 2007).

This study developed a femoral EMF model developed in a previous paper, which is the correct structural behavior of the femoral head (Aversa et al., 2016a) for the distribution of stress and tension on the stem and head and was modified to take into account resection femoral head and replacement with a Titan hip prosthesis for femoral fracture (Fig. 1). A comparison of biological stress and strain distribution in the femoral neck and femoral femur could help to understand the correct design procedures required for the design of new innovative biomimetic prostheses (Abdul-Razzak et al., 2012; Annunziata et al., 2006; 2008; Apicella et al., 2010; 2011; Davide et al., 2015; Aversa et al., 2009; 2016a-o; 2017a-c; 2019; 2020a; 2020b; 2021; Beaupre and Hayes, 1985; Bonfield et al., 1981; Cameron, 1986; Čepelak et al., 2013; Chen et al., 2012; Cormack and Tilocca 2012; Davis et al., 1991; Schwartz-Dabney and Dechow 2003; Duan et al., 2019; Filmon et al., 2002; Frost, 1964; 1990; 2004; Gorustovich et al., 2010; Gramanzini et al., 2016; Halpin and Kardos, 1976; Heinemann et al., 2013; Hutmacher, 2000; Hoppe et al., 2011; Hench, 1993; Hench and Polak, 2002; Hench and Thompson, 2010; Huiskes et al., 1987; Julien et al., 2007; Jones and Clare, 2012; Kim et al., 2004; Karageorgiou and Kaplan 2005; Kabra et al., 1991; Mano et al., 2004; Masteller et al., 2021; Mirsayar et al., 2017; Morales-Hernandez et al., 2012; Mourino et al., 2012; Montheard et al., 1992; Petrescu et al., 2019; 2015; 2016a-e; 2017; 2018; 2019a; 2019b; 2020; Petrescu and Petrescu, 2020; Petrescu, 2019; Perillo et al., 2010; 
Peluso et al., 1997; Prashantha et al., 2001; Reilly and Burnstain, 1974; 1975; Schiraldi et al., 2004; Schwartz-Dabney and Dechow, 2003; Sorrentino et al., 2007; 2009; Töyräsa et al., 2001; Wolff, 1892).

\section{Methods and Materials}

The CT-derived segmentation was performed using the Mimics software (Materialize, Belgium) to process the patient's CT. The solid anatomical pelvis and femur see Fig. 1 and 2, were obtained by processing CT data.

New prosthetic models using the combined use of the Mimics and 3-Matic programs (Materialize, Belgium) can be obtained from the biomechanical study of these bone marrow. The combined model of solid modeling and finite element analysis was developed in a previous paper by (Aversa et al., 2016a).
These methods simulate the structural morphology of the femur, as has already been done for other complex bone structures, which take into account the orientation and trabecular bone densities (Apicella et al., 2010; 2011; Davide et al., 2015; Aversa et al., 2016a; 2009; Beaupre and Hayes, 1985; Reilly and Burstein 1974; 1975; Huiskes et al., 1987; Taylor et al., 2007; Rohlmann et al., 1982). Several recent studies have highlighted the importance of GEF analysis in clinical applications and the development of new prosthetic systems (Mirsayar and Park 2016; Mazaheri et al., 2016) and the use of innovative materials and surface treatments (Kumar et al., 2016).

The methodological procedure is illustrated in Fig. 3-6. The external geometry of the femur and pelvic portion were reshaped creating a $3 \mathrm{D}$ volume of CT scans (Fig. 3).
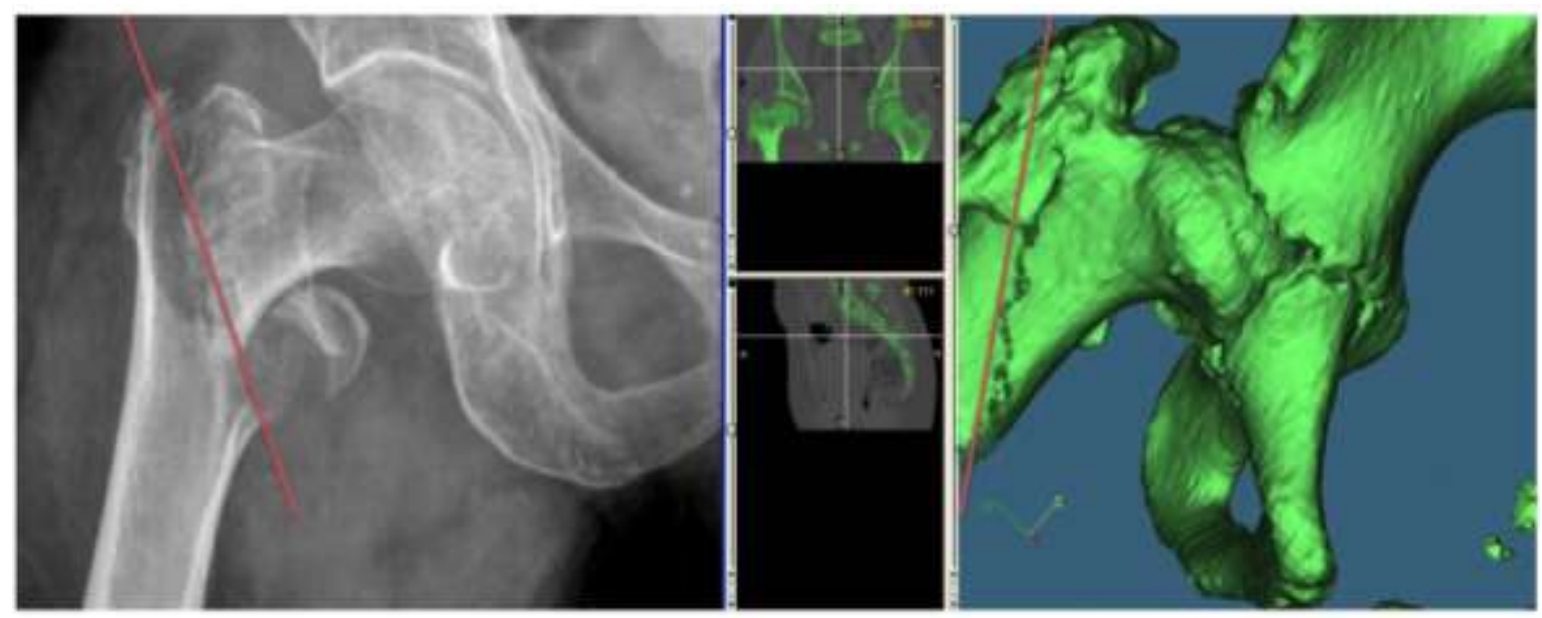

Fig. 1: Fracture planes (red line) of a pertrochanteric femur fracture (left CT) and solid modeling from software for CT segmentation in the proximal epiphysis-pelvis region

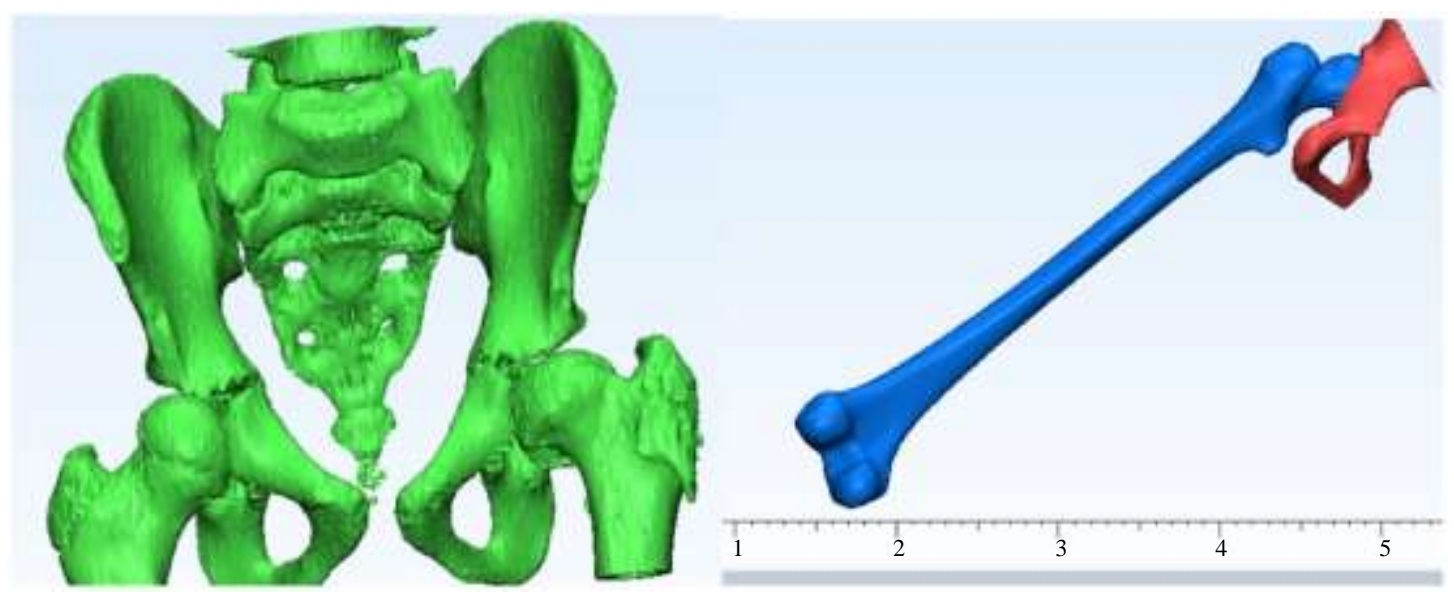

Fig. 2: Biofidel medical Image Segmentation of a patient pelvis and femur 


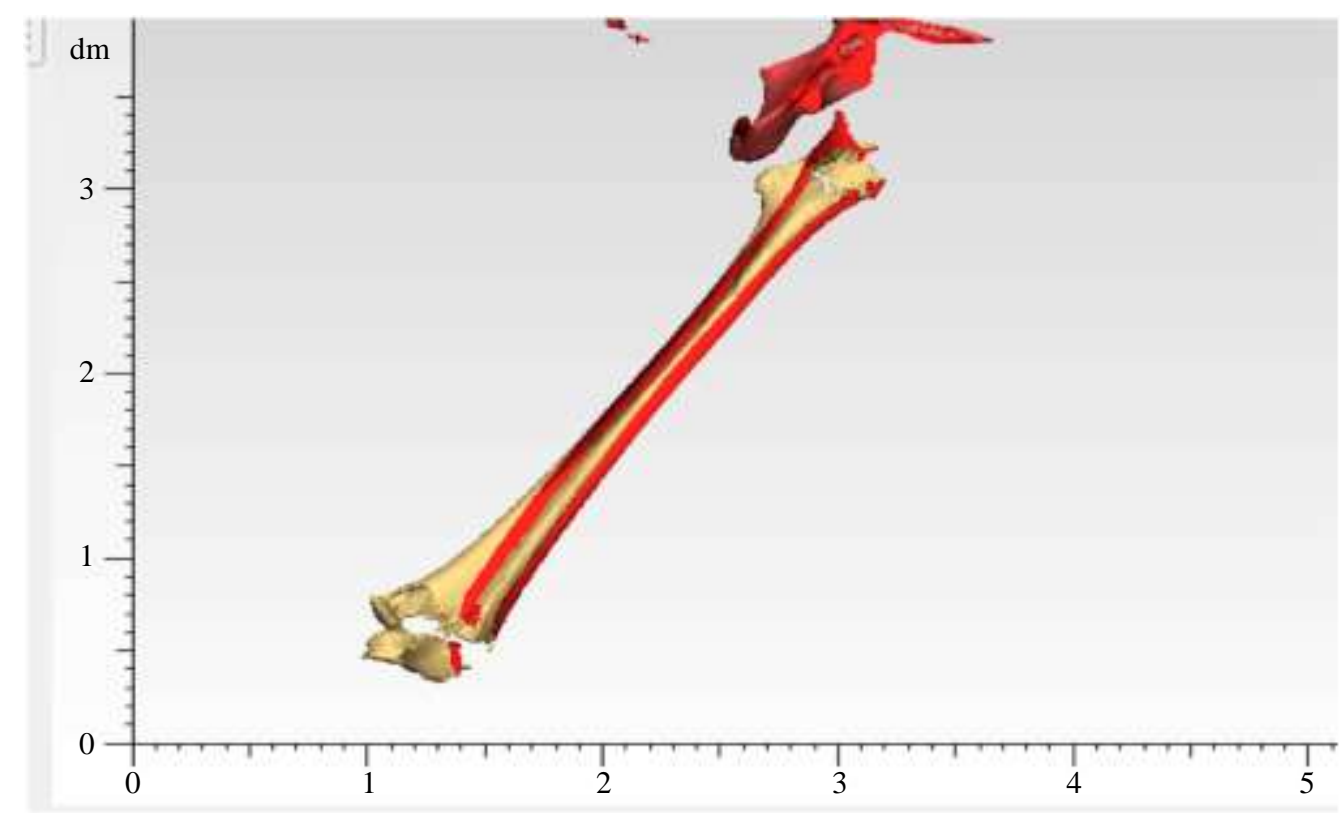

Fig. 3: Biofidel 3D solid modelling of a patient femur and pelvis
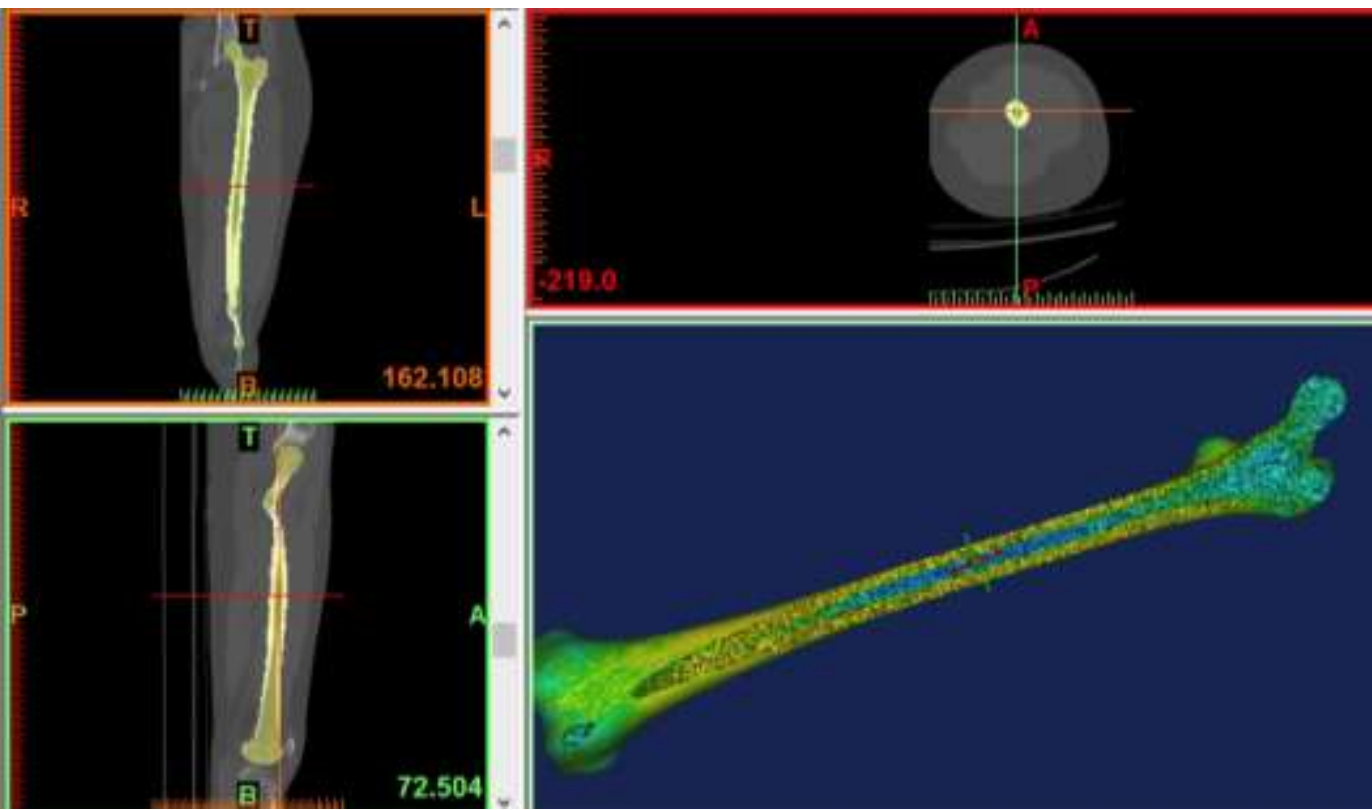

Fig. 4: Mesh creation and optimization of the biofidel not resected femur model (Aversa et al., 2016a)

The models were imported into 3 Matic software to create and optimize the surface and solid location, which was necessary to prepare the finite element model and to designate the properties of the material (Aversa et al., 2016a).

The results of the distribution of the material of the tetrahedron elements are presented in Fig. 4. The same procedure was applied to the preparation of the FEA model of the femur with head resection (Fig. 5), which was practically related to the fracture plane reported in Fig. 1 and for traditional prostheses in the titanium hip joint (reported on the left side of Fig. 6).

The model of the resected femur and the titanium prosthesis was made by defining the optimization of the 3D tetrahedral meshes of distribution and size, as indicated in the right part of Fig. 5 and 6 , respectively. 

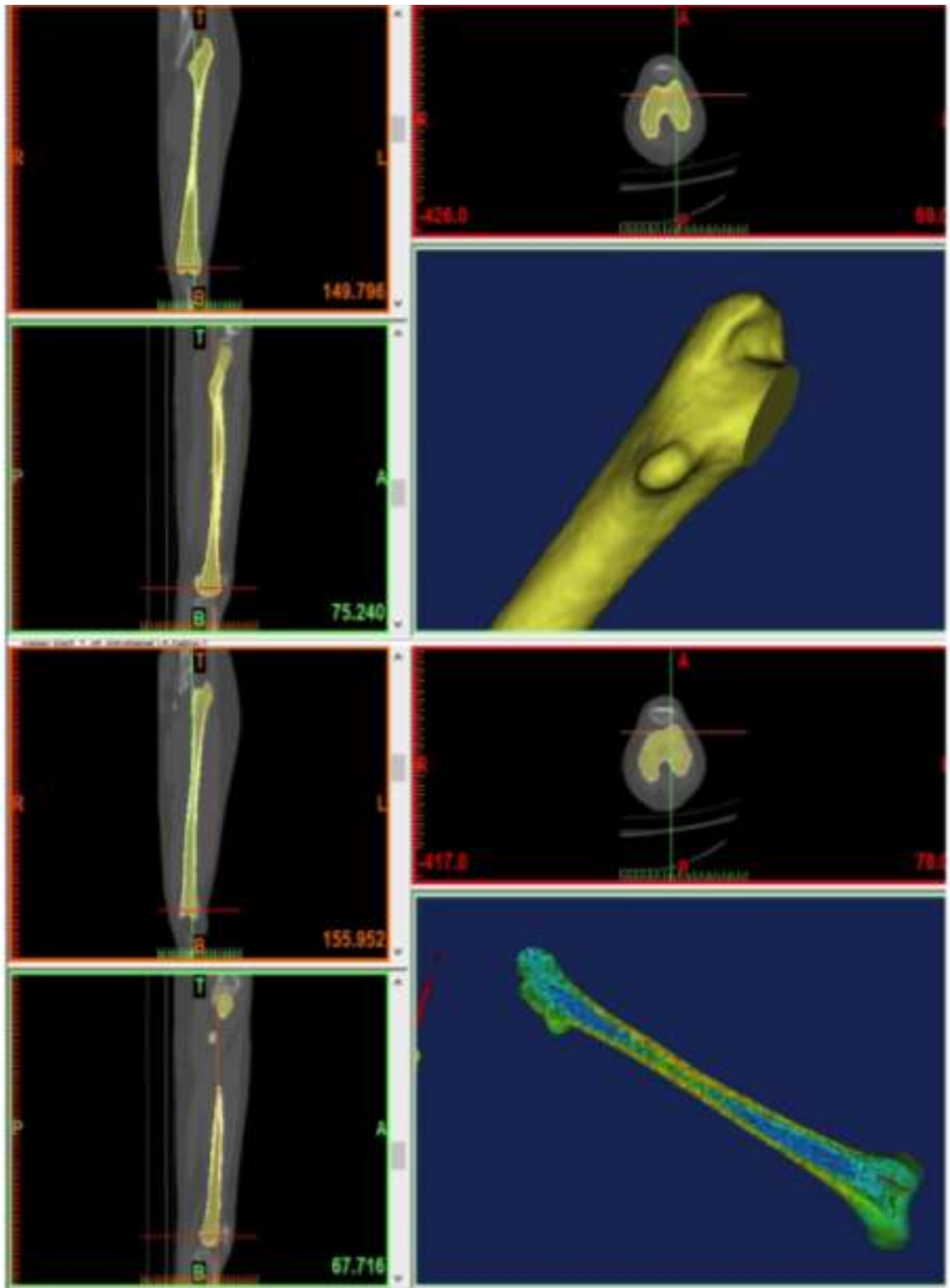

Fig. 5: 3D meshing optimization of the biofidel patient femur model

The solid mesh elements of the resected femur were associated with bone densities, such as measured by a Hounsfield (HU) scale, which calculates linear X-ray attenuation coefficients in tissues, using Mimics software (bottom of figure). Solidly placed models of resected femoral prostheses and $\mathrm{Ti}$ were assembled to correctly position the implant using Mimics software (Fig. 7).

The new remodeling of the tetrahedral elements was performed in 3Matic (Fig. 8) looking for the congruence of the node at the bone-implant interfaces, where the material was defined for the new configuration of the finite elements. The evaluation of the mechanical properties was made taking into account the mechanical characteristics of the cortical and trabecular bone.

The absence of stress (and state-related state) could induce a significant change in bone structure over time (bone resorption). In fact, bone modeling and remodeling processes allow themselves to grow, renew and repair (Gottesman and Hashin, 1980; Huiskes et al., 1987; Taylor et al., 2007; Weinans et al., 1992). The mechanical adaptation of trabecular density and architecture could be explained in terms of mechanicalsensory and signaling functions for osteocytes (Mullender and Huiskes, 1995). The mechanism of 
mechanical regulation leading to bone remodeling uses mechanical stress and micro-damage as a stimulus that determines cellular responses and consistent changes in bone density and geometry. The absence or modification of the biomechanical stimuli shown in Fig. 10 for the femoral shaft after implantation of the prosthesis is then expected to lead, over time, to bone remodeling and reabsorption due to the absence of adequate stress and tension.

Validating the clinical efficacy and estimating the long-term reliability of restorative prosthetic systems requires an adequate understanding of the physical variables that influence the biomechanical behavior of the material for advanced biomedical applications.

The Finite Element Analysis tool (FEA) allows biomaterials to obtain a complete assessment of the biological and mechanical behaviors of advanced restoration systems, even for inhomogeneous systems. If validated by appropriate experimental procedures, the FEA becomes useful for optimizing the design criteria for restoration and the choice of materials to be used. Moreover, this method allows estimating the location of the fracture in the circumstances of data loading (Aversa et al., 2016a).

New manufacturing processes based on additive manufacturing technologies and studies on biomechanics and biomimetics (Annunziata et al., 2006; Apicella et al., 2010; Aversa et al., 2009) could allow the establishment of new design criteria for human prostheses. The authors took these studies to gather the untapped potential of such advanced materials and design technologies by developing finite models of Biofidel elements capable of correctly mimicking the biomechanical behavior of the femur (Fig. 11).
Although the human femur has an internal structure capable of withstanding high external stresses, the evolution of mass and the arrangement of cortical and trabecular bone types (Gottesman and Hashin, 1980; Oh and Harris, 1978; Dalstra et al., 1993), the progressive loss of physiological bone mass in the elderly or in the presence of prolonged inactivity results in bone weakness and reduced ability to withstand mechanical shocks. This reduced resistance is the main cause of pertrochanteric femoral fractures in the elderly (Ashman and Rho, 1988; Burstein et al., 1976; Carter and Hayes, 1977). Reducing these fractures and restoring the functionality of the hip joint requires the application of a special prosthesis. It is currently possible to completely replace the hip in patients under the age of 65 and therefore a longer life expectancy, which requires longer durability of the orthopedic implant (which now does not support more than 15 years).

Orthopedic prostheses used today are made of metal alloys, plastics and ceramics with well-defined properties and characteristics. In particular, due to their high biocompatibility and high mechanical strength, certain metal alloys based on titanium chromium or cobalt are commonly used and represent almost all prosthetic components. These traditional prosthetic products are made from valuable technologies, such as forging or smelting metals, followed by mechanical processing. These processes do not allow optimal design solutions for better biomechanical bone integration. The application of other structures on surfaces to create a more osteoinductive and osteoconductive substrate for healthy bone growth should necessarily be done (Schiraldi et al., 2004; Gramanzini et al., 2016).
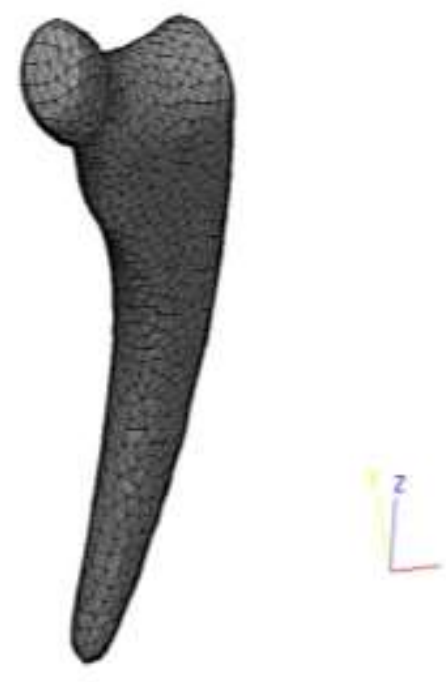

Fig. 6: 3D meshing optimization of a Titanium traditional prosthesis 


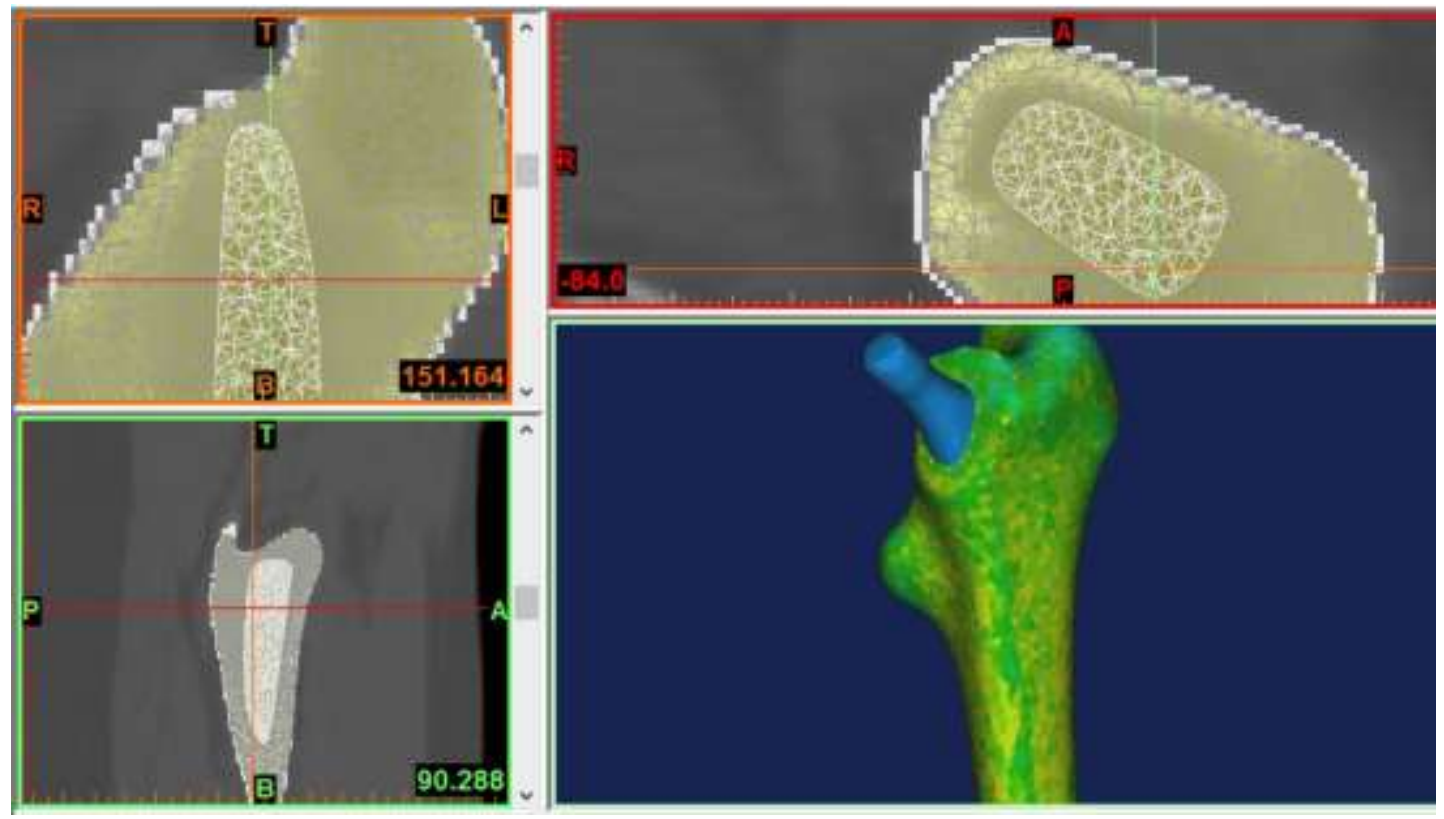

Fig. 7: Assembly and material properties definition associated to the patient femur cortical and trabecular bone densities and to the Titanium prosthesis

However, these processes, although very expensive, do not provide sufficient structural support and are often not mechanically adequate. Metal implants, on the other hand, can allow for a rapid and satisfactory structural restoration of functional mobility, while maintaining acceptable operating costs. However, in addition to high invasiveness, these implants are not the ideal solution, especially for younger patients with long life expectancy, both in terms of duration and biomechanical Osseointegration. This first generation of the prosthesis is not technically the optimal structure for optimal optical and biomechanical integration with the bone tissue in the area around the implant.

By comparing a metal prosthesis with one with human bones on radiographic examination, the difference in density and mass that can induce healthy bone growth (Davide et al., 2015) is obvious.

Frost (1964), states that the adaptive properties of bones depend on the range of physiological strains to which the bone is subjected. The location of the implant can promote resorption processes that lead to a larger and more unstable state until the prosthesis shows signs of weakness, will move from its position, causing serious consequences and pain for the patient. In more severe cases, the implant fails, requiring immediate replacement.

\section{Biomechanics and Biomimetics: A Way to Promote Advanced Materials and Advanced Technologies}

Implants are then expected to last a much longer period without failure or surgical revision. The design and improvement of appropriate combinations of prosthetic materials and systems that demonstrate enhanced strength and biocompatibility become mandatory.

The prosthetic bone of the resected bone is expected to provide an "equivalent rigidity" (the combination of the elastic modulus of the material and the shape of the prosthesis) that matches that of the missing bone and the prosthesis in which it is implanted.

Due to the orthotropic density and the different density of the structure, the elastic bone modulus can vary from 4 to $20 \mathrm{GPa}$, which depends on the type of bone and the direction of loading. The metallic materials and ceramic implant adopted today, characterized by a higher rigidity than bone at implantation, strongly modify the local stress of the physiological distribution of unwanted bone resorption through the implant and, therefore, the increased risk of implant failure. This biomechanical mismatch reduces the level of biological demand for healthy bone growth (Frost, 1994) and bone loss due to this reduced load, known as stress protection.

For biomechanical integration of the implant, a custom material with an improved combination of strength and rigidity that matches the bone should be used. This greater biomechanical compatibility will avoid weakening the implant and increase lifespan, avoiding additional surgery for revision and allowing good biological integration (bone growth).

Innovative biomimetic materials for tissue engineering based on hydrophilic polymers were developed by our research group and presented attractive physical, biological and mechanical properties for biomedical applications (Schiraldi et al., 2004). For use with metal 
prostheses, the authors have developed a hybrid biocompatible material, extremely biocompatible, based on hydrophilic chemicals and hydroxy-ethylmethacrylate type.

The structural metal composition of the new prostheses will be made of titanium alloys using additive technology based on melting thin layers of titanium powder (about 50 microns) on each other until the desired component is obtained (sandwich method). Then, the biomaterial and osteoconductive nanostructured material developed in our previous studies (Schiraldi et al., 2004) can cover the titanium structural prosthetic skeleton. These hybrid biological prostheses, which are made using synthetic materials capable of inducing the growth of biological networks and structural steel scaffolding, may favor the emergence of new classes of orthopedic hybrids in the medical field. The new hybrid bioprosthesis could drastically reduce protection against stress while providing an advantageous improvement in the life of the prosthesis compared to traditional solutions. Recovering optimal joint functionality will improve the patient's quality of life, which perceives a significant reduction in the risk of the new surgery. The requirement to predict potential structural changes that could be induced by improper use of biologically compatible prostheses in bone structure and morphology has forced our studies to evaluate fictitious models that could be considered for efficient bone distribution and orthotropic behavior (Aversa et al., 2016a).

The development of loyal models has already allowed us to prepare prostheses that could restore natural stress and physiological bone strains (Apicella et al., 2010; Gramanzini et al., 2016; Perillo et al., 2010).

In this study, a femoral FEM model was developed that was developed in a previous paper to represent the exact structural behavior of the femoral head (Aversa et al., 2016a) for stress distribution and strains along the stem, head resection femoral and Titan, joint replacement. A comparison of biological stress and strain distribution in the femoral neck and femoral bone could help to understand the correct design procedures needed to design new innovative biomimetic prostheses.

Medical image segmentation was derived from CT using Mimics software (Materialize, Belgium) to process a medical image of the patient. As shown in Fig. 2, CT processing led to a solid model of the patient in the pelvis and femoral anatomy. New applications of prosthetic engineering through the combined use of the Mimics and 3Matic programs (Materialize, Belgium) could be derived from the biomechanical study of these bones.

A 3D model with solid Finite Element (FEM) was developed in a previous paper that simulates internal and external femoral morphology, as has already been done for other complex bone structures corresponding to the orientation and densities of the trabecular systems of the head (Aversa et al., 2016a; Apicella et al., 2010; Beaupre and Hayes, 1985; Reilly and Burstein, 1974; 1975). The procedure is illustrated in Figs. 3-6. The external geometry of the femur and pelvis was reconstructed by generating a three-dimensional volume that interpolated CT scans (Fig. 3).

The results were then imported into 3Matic software for optimizing surfaces and solid surfaces, modeling finite elements and defining material properties (Aversa et al., 2016a; Apicella et al., 2010; Davide et al., 2015).

The results of the distribution of the material of the tetrahedral element have already been presented in Fig. 4 (yellow corresponds to the different rigidities of the mechanical properties of the cortical bones, while the green ones are the trabecular bone of different densities). The same procedure was applied to the FEM model for resection of the femoral head, practically performed on the fractures reported in Fig. 1 and for traditional titanium prostheses. Internal modeling of the resected femur and meta-prosthesis was performed by defining the three-dimensional distribution of internal language optimization and language size, as shown at the top of Fig. 5. Massive femoral cross-links were sequentially associated with patient bone densities, according to the Hounsfield scale (HU). This scale quantifies the X-ray attenuation coefficients in the tissues, assigning (using Mimics software) the elastic modulus corresponding to the corresponding elements of the FEM model (bottom of Fig. 5). Massively resected femoral models and $\mathrm{Ti}$ prostheses were assembled to position the implant correctly using specialized Mimics software (easily handled by our colleague Aversa). The new mosaic of tetrahedral elements was made in 3Matic in search of nodal congruence at the implant-bone interface. The mechanical properties were assigned taking into account the cortical and trabecular bone characteristics.

In particular, the systems were considered isotropic materials and the mechanical properties were coupled to each tetrahedral element characterized by the equivalence of the Hounsfield (HU) density scale. The elastic and shear modules of the trabecular bone were derived as a fraction of those of the cortical bone with a direct proportionality to the porosity measured by axial tomography. In this scale, the value of fat is about 101, muscles around 40, trabecular bone remains between 100 and 300, while the cortex covers the values between high-density cortical bone (300) and about 2000, which fall into the bone systems at the elastic modulus ranging from 0.87 to $15.0 \mathrm{GPa}$. The solid mesh elements of the trabecular-oriented material were assigned by operating on the internal structure that explains the actual trabecular morphology of the bone that we found at the proximal end (Fig. 12) as indicated in (Aversa et al., 2016a). 


\section{Ti Prosthesis Design with Variable Rigidity}

To avoid the excessive protective effects of stress on the resected femoral shaft (shaft), the trabecular hip joint prosthesis has been properly designed according to the characteristic and specific rigidity of each section of the diaphysis affected by the prosthesis.

The mechanistic model of the proximal hip epiphysis proposed by (Kummer, 1986) was transferred to the design of the hip joint prosthesis where the presence of isostatic lines characterizing the oriented trabecular systems is reported in Fig. 13 from the left).

Furthermore, the biomimetic prosthesis should have stiffness along the isostatic lines that match those of the bone where it is placed. Five regions of the prosthesis were chosen to assign differentiated decreasing stiffnesses (right side of Fig. 13).

The stress of the state acting on the system and the observation of the isostatic lines described by (Kummer, 1986) was used to define the porosity morphology that characterizes the trabecular structure of the stem and head of the prosthesis in different areas.

These regions should be characterized by variations in stiffness that progressively decrease from a very rigid head (region 1 in Fig. 13) to extremely flexible (region 5 in Fig. 13).

The isostatic lines and morphological differences of the trabecular regions of iso-rigidity are better appreciated by comparing the trabecular structure of the isostatic and iso-rigid regions (Fig. 14b and 14c).

The orientation and different shapes of the porosity of the titanium cigar are evident in the internal structure shown in Figs. 10b and 10c.

An example of a trabecular iso-rigidity structure obtained by sintering $\mathrm{Ti}$ alloy powder through the electron beam is shown in Fig. 10d. Apparent elastic patterns of trabecular structures in iso-rigidity regions range from 20 GPa for regions 1 to $11,8,4$ and $1 \mathrm{GPa}$ for regions 2, 3, 4 and 5 , respectively.

The orientation of the trabecular system visible in the lower left of Fig. 14b seen in the area of the prosthetic stem corresponding to the femoral-tibial epithelium during tension would maintain and ensure the necessary continuity of stiffness in each specific region shown in Fig. 14a. The previously calculated $\mathrm{CT}$ values of bone densities were then correlated with the isostatic lines of cortical and trabecular bone of femoral and femoral bone resection, taking into account each tetra-medley-oriented mesh along the isostatic stress directions observed in the proximal femoral epiphysis. Similarly, the same criterion (isostatic orientation) was used to define titanium.

FEM analysis: Femoral teeth and tears and femoral teeth.

Based on 3D models of the femur and femur, resected with rigid and flexible prostheses, a structural evaluation was performed under the same loading conditions and the results were critically compared.

The characteristic biometric parameters of the patient's hip system were performed before the structural analysis. 3Matic software was used to identify the direction of the loading axis, the center of the proximal sphincter of the headspace and the common center of the epicondylar axis and the mechanical axis of rotation of the knee.

The following parameters were measured: The mechanical axis between the centers of the proximal and distal epiphyses, the angle of $143.4^{\circ}$ between the femoral axis and the diaphysis axes and the divergence of $36.65^{\circ}$ between the neck axis and the epicondyle axis.

Finally (before the FEM structural analysis) physiological tasks and constraints were assessed.

\section{Load Condition and Constraints Imposed}

The balance of the steady-state was considered a very serious loading condition, with a rotation around the center of the hip joint when the gluteal muscle force balances the pulse transmitted by body weight. Given the patient's weight of $100 \mathrm{~kg}$, the gluteal muscle force applied to a large trochanter is $1800 \mathrm{~N}$ and the hip response force is $2740 \mathrm{~N}$ (these values were calculated based on biometric data in Fig. 15).

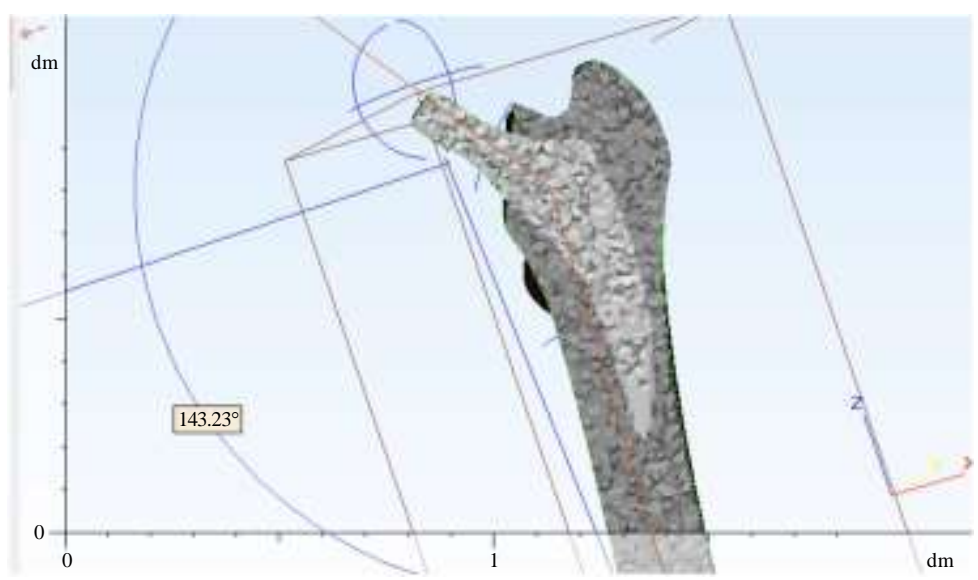

Fig. 8: Assembly of the resected femur and Titanium rigid hip prosthesis and tethraedric mesh congruency verification 


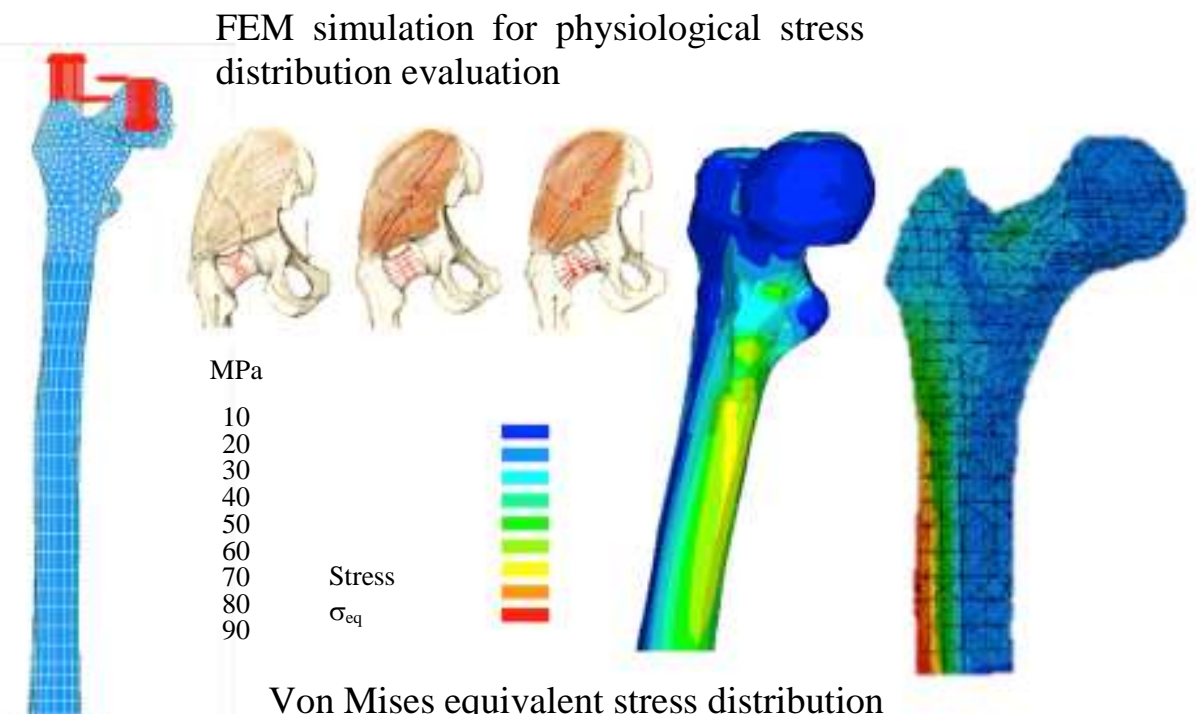

Fig. 9: Phisiological Equivalent Von Mises stresses in the femur from our biofidel Finite Element Model

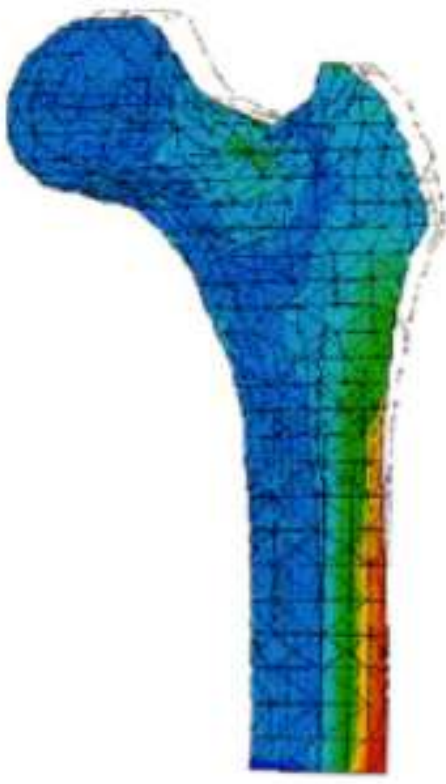

(a)

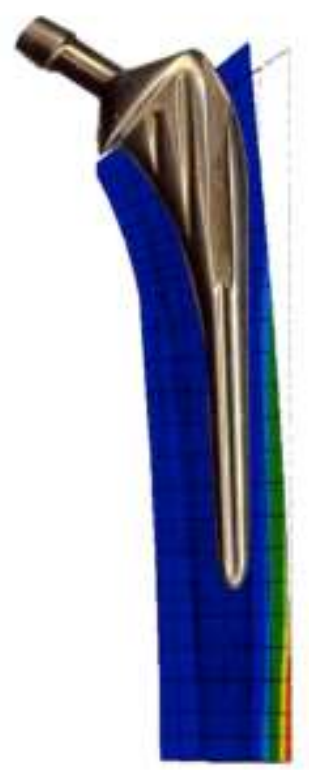

(b)

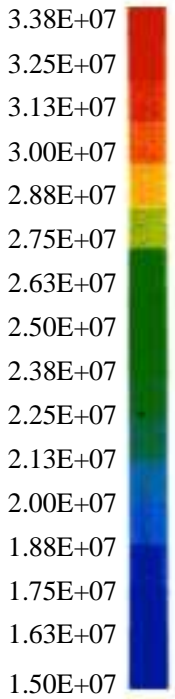

$1.50 \mathrm{E}+07$

Fig. 10: Equivalent Von Mises stresses distribution in the proximal femur epiphysis for (a) sound femur, (b) rigid Ti prosthesis

The resistance of the gluteus muscle could be evenly distributed around 100 nodes in the larger FEM trochanter, while the common hip response force could be spread over 50 nodules of the femoral head (see Fig. 9 above). In this study, we defined the procedure for preparing a biophysical model of the femur capable of correctly describing its structural biomechanical behavior. The Von Mises strain criterion was used to compare and validate new flexible trabecular projections. Von Mises is an energy criterion that can accurately quantify the ability of bones to withstand heavy loads (Fig. 9).

The different structural behaviors of the two models are also evident in the distribution of Von Mises stress, clearly different in the posterior and anterior part (right end in Fig. 9 and Fig. 16a). The distribution of posterior tension confirms the presence of bending effects with the highest homogeneous values distributed in the regions of the anatomical diaphysis (Fig. 16a). 

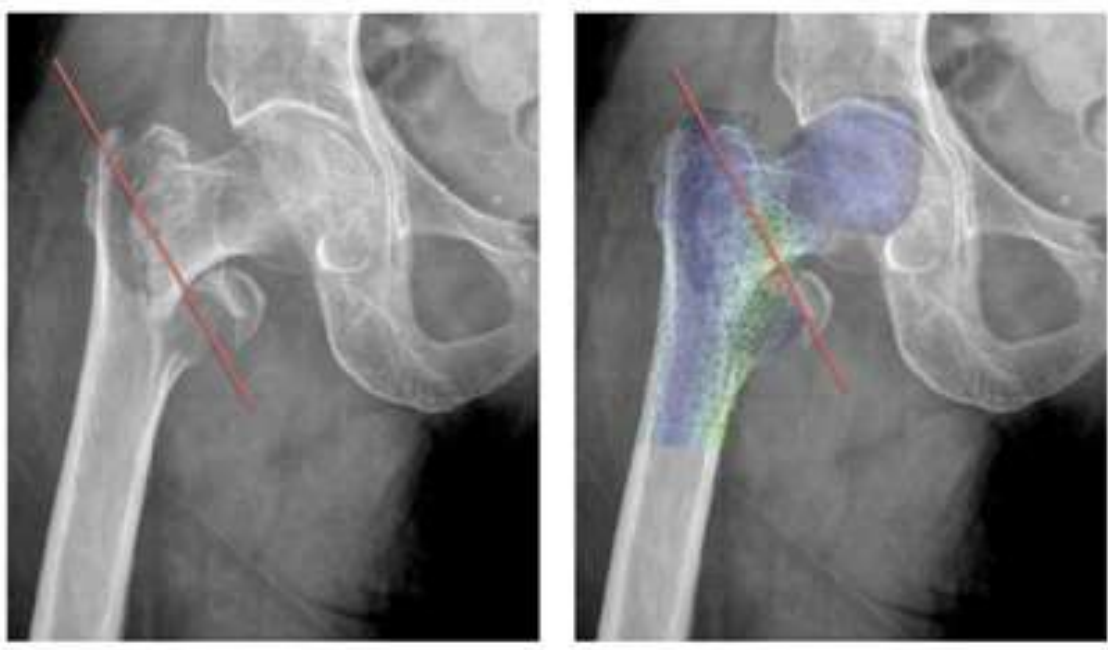

Fig. 11: Fracture plane of a pertrochanteric femur fracture (left) and FEA from Aversa et al. (2016a)
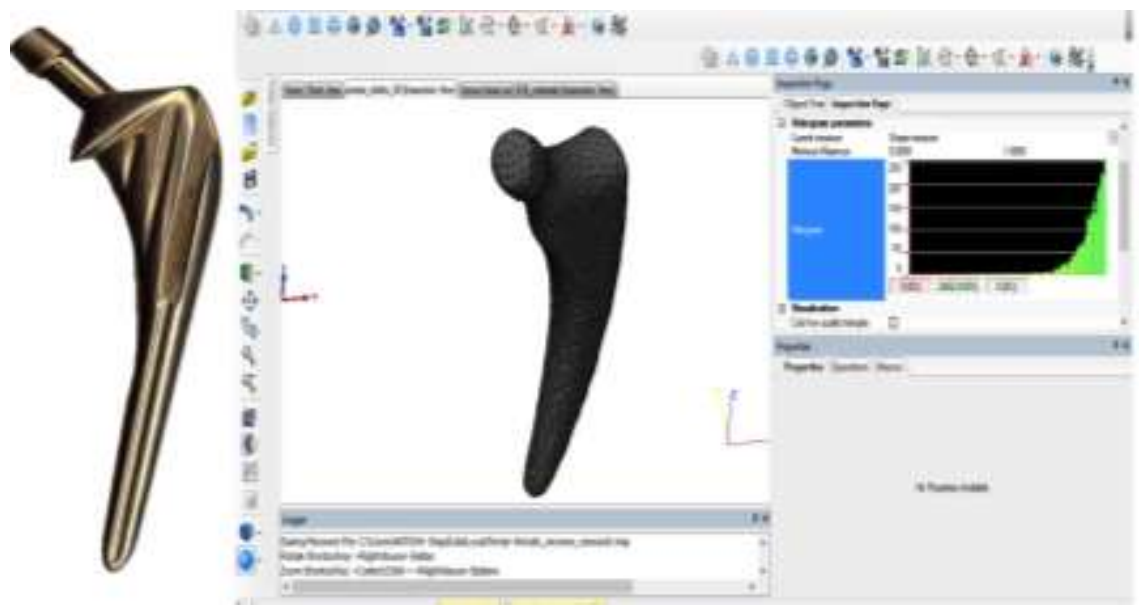

Fig. 12: 3D meshing optimization of a Titanium traditional prosthesis
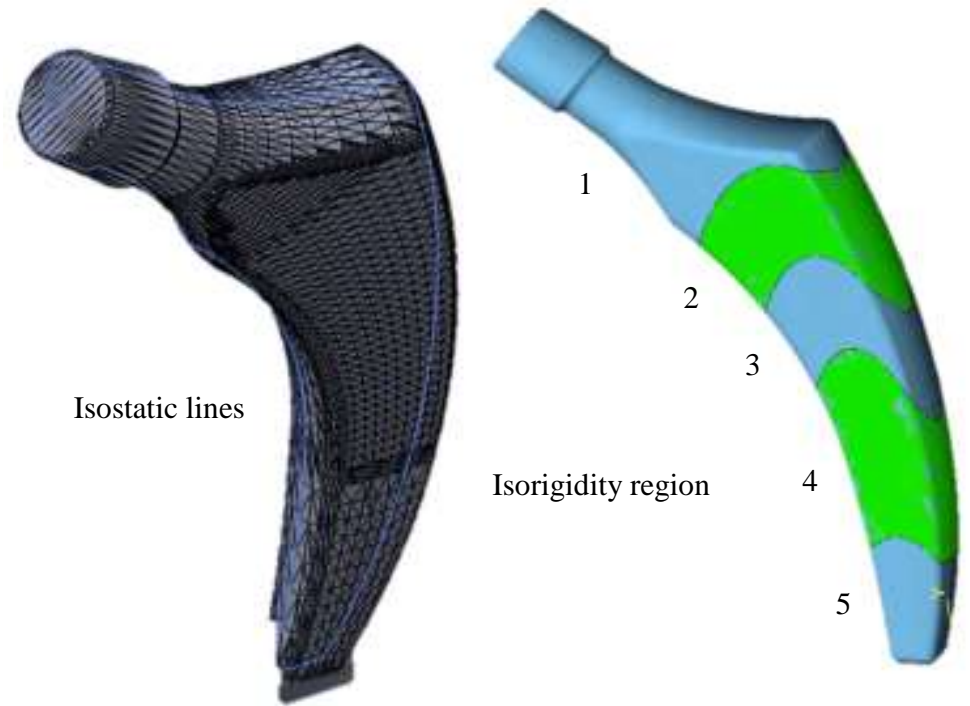

Fig. 13: Left, Isostatic lines (Kummer, 1986) and right, Isorigidity regions chosen for the biomimetic prosthesis trabecular structure design 
(a)

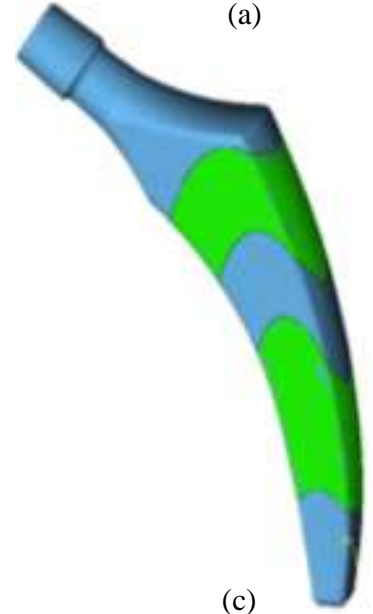

(c)

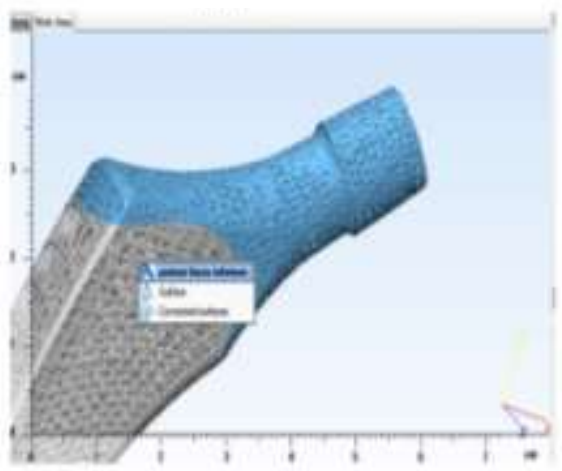

(b)

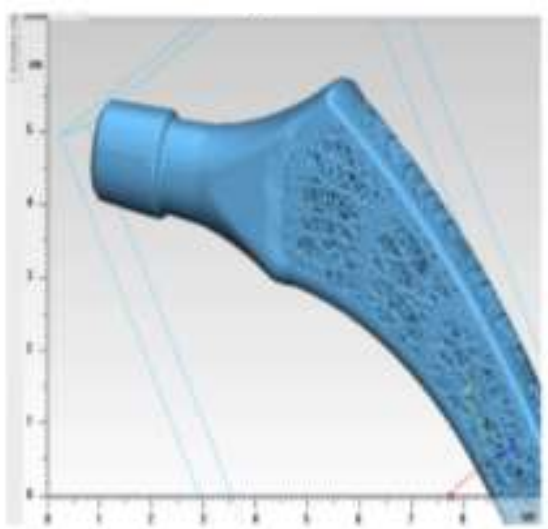

(d)

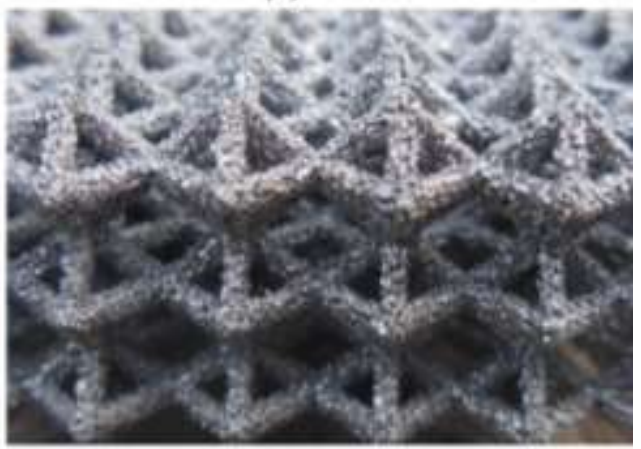

Fig. 14: Flexible trabecular hip joint prosthesis with different stem and head rigidities and orientations. (a) Region of equivalent stiffness, (b) the overall flexible prosthesis, (c) internal trabecular structure, (d) Orthotropic trabecular structure obtained by additive sintering of Ti powders

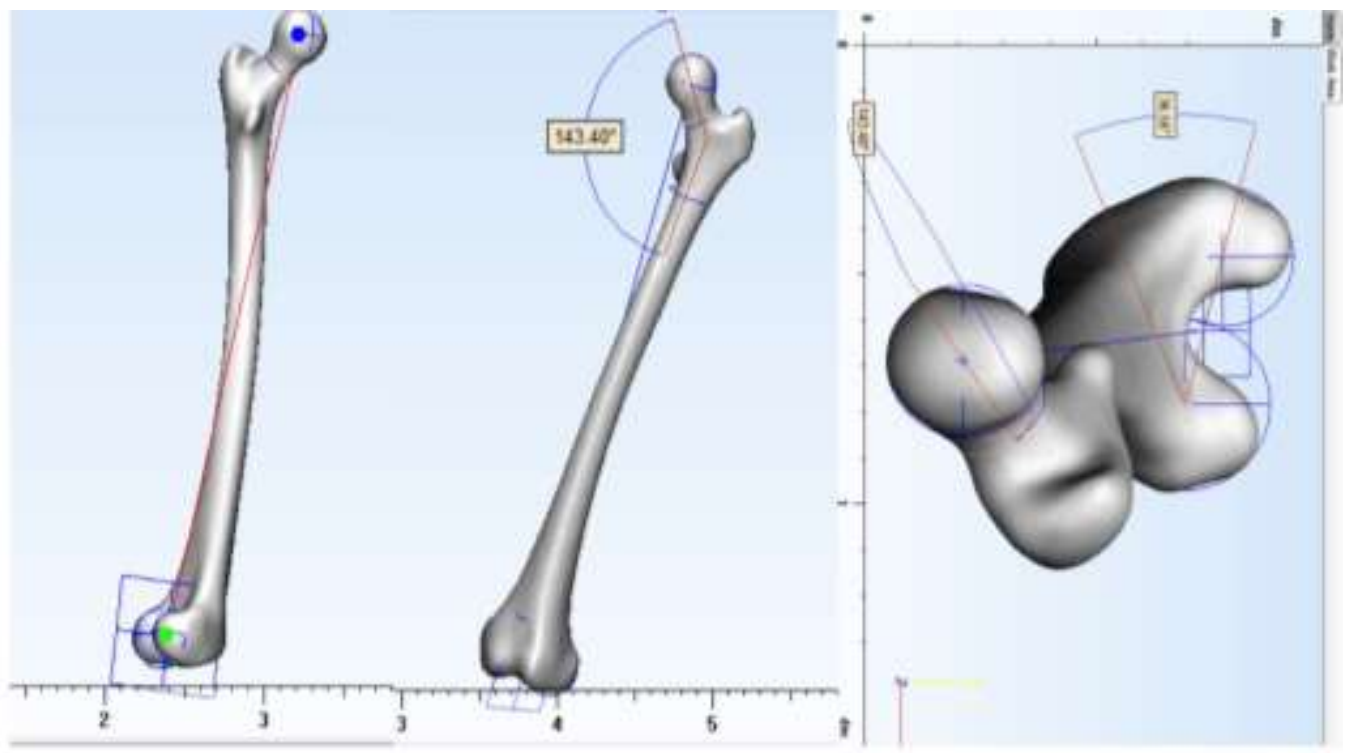

Fig. 15: Biometric analysis (Aversa et al., 2016a): Mechanical axis of the femur (left); Angle of the femoral neck $\left(143.40^{\circ}\right.$, Center); Angle of divergence of the neck with the axis of epicondyles $\left(36.65^{\circ}\right.$, Right) 


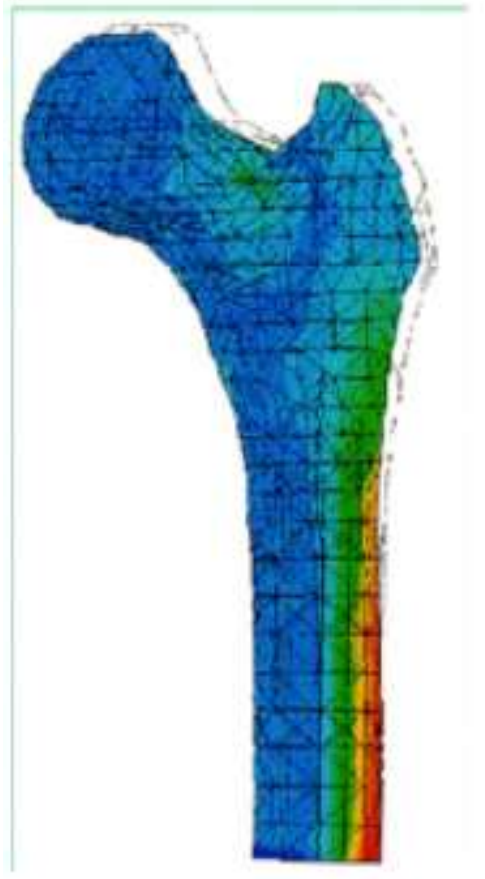

(a)

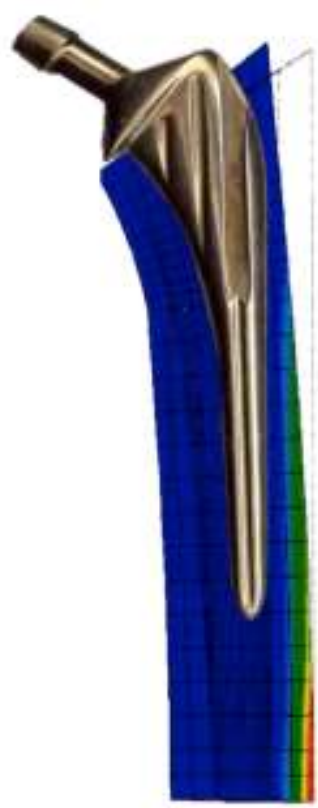

(b)

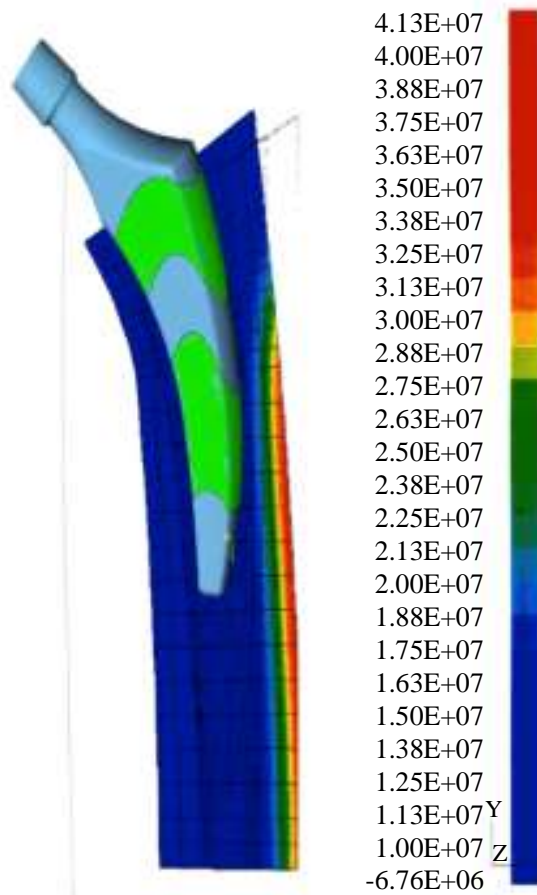

(c)

Fig. 16: Equivalent Von Mises stresses distribution in the proximal femur epiphysis for (a) sound femur, (b) rigid Ti prosthesis and (c) flexible trabecular prosthesis

\section{Results}

Biomimetics, biomechanics and tissue engineering are three multidisciplinary fields that have been considered in this research to achieve the goal of improving the reliability of prosthetic implants. Because testing and mathematical methods are closely linked, a promising approach seemed to be the combination of in vitro and in vivo experiments with computer simulations (in silico). An innovative approach to biomimetics and biomechanics is presented, as well as a new synthetic structure that ensures a microenvironment that is mechanically coherent and promotes tissue osteoblastic cell cultures used in regenerative medicine. The new ceramic-polymer hybrid nanocomposites are mutually researched by biomimetic modeling of Finite Element Analysis (FEA), anatomical reconstruction, quantitative-computerized characterization of tomography, computerized design of the tissue scaffold. The raw materials are a class of extremely bioactive hybrid ceramic-polymeric materials, established by the proposing research group, which will be used as a bioactive matrix for the preparation of bio-mineralized tecto-structured porous nanocomposites in situ.

This study treats biomimetics, biomechanics and tissue engineering as strongly correlated multidisciplinary fields combined for bone tissue scaffold design. Bone growth, maintenance and ossification are fundamental and are regulated by mechanical indices imposed by physical activities: This biomimetic/biomechanical approach will be pursued in the design of experimental procedures for in vitro mineralization and scaffold ossification.

Mathematical modeling of biological tissues serves as a central repository for interface design, simulation and tissue fabrication. Finite element computerized analyzes will be used to study the role of local tissue mechanics on endochondral ossification patterns, skeletal morphology and mandibular thickness distributions using representations of continuous single-phase and multiphase material of clinical cases of patients implanted with traditional protocols. The new protocols will be hypothesized for the use of new biologically tecto-structured hybrid materials. Medical Image Segmentation for Engineering application has been derived using the Mimics software (Materialise, Belgium) for processing patient medical image coming from CT. As reported in Fig. 17, the processing of CT resulted in a highly accurate $3 \mathrm{D}$ model of the patient pelvis anatomy. This patient-specific model has been processed to develop new prosthetic engineering applications through the combined use of Mimics and 3-Matic (Materialise, Belgium) software. Namely, 3D 
solid and Finite Element Models (FEM) have been developed to simulate the external and internal morphology of the femur and other complex bone structures accounting for the orientation and densities of the head trabecular systems (Aversa et al., 2009; Apicella et al., 2010; Beaupre and Hayes, 1985; Reilly and Burstein, 1974; Reilly and Burnestain, 1975). The procedure is illustrated in Fig. 18 to 21 . The external geometry of the femur has been reconstructed by generating a three-dimensional volume that interpolates the CT scans (Fig. 18). The results were then imported in the 3Matic software for surface and solid meshing optimization as indicated in Fig. 19. Internal modeling of the entire femur has been realized by defining three-dimensional internal tethrahedric meshing distribution and size optimization (Fig. 20). A correlation of the mesh solids was ensured, being successively associated with the bone densities measured according to the Hounsfield scale (HU), by quantifying the linear X-ray attenuation coefficients in the tissues and then assigned to the FEM model by the Mimics software (Fig. 21).

The evaluation of the mechanical properties was made taking into account the characteristics of the trabecular bone. The systems were considered transverse isotropic materials, with elastic and shear modulus expressed in terms of cortical bone values and elastic modulus and shear values were then evaluated by multiplying cortical bone values by the defined porosity for each tetrahedral element with the Hounsfield density scale (HU). On this scale, as already mentioned in the paper, the thickness is about 110 , the muscle is about 40 , the trabecular bone is between 100 and 300 and the cortical bone extends beyond the values of the trabecular bone to about 2000. Bone tensions can be modulated by choosing the thickness of the scaffold swelling for healthy bone growth. In vivo tests performed using these new modified oral implants confirmed the improved capacity of these implants in promoting early osseointegration (Gramazini et al., 2016).

\section{Biomimetic/Biomechanical Approach: Hybrid Ceramic-Polymer Surface Design and Bulk Properties to Improve Osseointegration}

Bio-prosthetic devices are a reconstructive therapy widely used in clinical practice in many areas of rehabilitation surgery, such as dentistry, maxillofacial surgery, orthopedics. The interface between bone and implant has been a subject of study for many years, as we try to move from bioinert to bioactive biomaterials. In fact, the histological analysis performed in these years does not allow the confirmation of theories about a possible contact, through junction systems and others.
However, there is fluid contact between the osteocytic canalicular surface and the implant surface. Bioactive biomaterials could promote and improve the differentiation from an osteoblastic phenotype, which becomes during surgical healing of wounds caused by the implant, thus having a better osseointegration in shorter periods. Recent studies describe the characteristics of nanostructured materials that could promote osseointegration:

- Carbon and alumina nanostructures, which mimic the nano-dimensional geometry of hydroxyapatite, increase osteoblastic activity and thus produce greater bone deposition when applied to orthopedic implants

- Nanostructured biomaterials, which mimic the bioactivity of the hydroxyapatite crystal, promote the adhesion and production of alkaline phosphates in osteoblast-like cells

So, further studies on these materials could lead to better and shorter healing to promote protocols that ensure early and immediate loading. The composition and properties of the surface appear to be important because they appear to modulate the response of the osteoblastic cell that affects tissue healing (Davis et al., 1991; Gramazini et al., 2016; Aversa et al., 2016b). Periimplant tissue adjusts its composition and architecture according to its functional capacity (Apicella et al., 2011; Davide et al., 2015). Therefore, a key to the success of the titanium implant in bone integration appears to be whether the bone is adequately reshaped at the periphery of the implant (Aversa et al., 2016b).

Figure 22 shows the result of "in vivo" experiments performed on dental implants placed on a white rabbit femur. In particular, the experiment described in Aversa et al. (2016b) consisted in evaluating the osteoinductivity and osteoconductivity of $\mathrm{Ti}$ implant surfaces without and with a thin coating of 100 microns from our ceramic-polymer hybrid material. Bone implant placement or bone growth (Cameron, 1986), which is defined as the percentage of osseointegrated implant length for biomimetically coated implants and found in six-month in vivo tests, shows a significant improvement. Micro-CT bone reconstruction of bone growth around the implant was validated using FEAcalculated physiological strain distributions. The maps of the colored strains around the bone surrounding the implant confirmed the critical role of the Ti-Bone bioactive interface. Osteoblast proliferation and bone growth in the implanted rabbit femur is clearly favored and accelerated by the presence of the nanostructured hybrid layer. The biomechanical approach using the adaptive properties of bone describes the biomimetic behavior of the proposed perimeter hybrid scaffold, as 
it can predict areas of bone resorption (FEA model elements with strains below physiological lower limits were removed in the image, right side of Fig. 22).

Research has shown that mechanical stimulation can have a profound effect on the differentiation and development of mesenchymal tissues. Figure 23 illustrates the adaptive properties and values of the stem threshold for healthy bone growth.

According to (Frost, 1990), who quantified (Wolff's, 1892) observations, above (>3000 microepsilon) and below ( $<50$ microepsilon) critical levels of the strain, bone growth is affected. In the light range of strains, healthy bone growth and regeneration is favored. In fact, in order to maintain the stability of the implants under load, it is of major importance for the osteoblast that forms the bone to promote the extracellular matrix in the vicinity of the implant.

\section{Mechanisms of Osseointegration to be Considered in Biofidel Models}

Implant osseointegration is essential for prosthetic rehabilitation. Achieving and maintaining stable functional ankylosis has the following morpho-structural characteristics, namely: -direct contact between bone and implant, in the absence of an adequate tissue interface; the existence of the primary bone in contact with the surface of the biomaterial; -deposition, outside the primary bone layer, of the secondary lamellar bone in contact with the titanium surface; -total increase in peri-implant bone density compared to the normal bone architecture of the region; -increased spinal cord space, which is necessary to deplete the metabolic need of the tissue in the region less involved in pregnancy dissipation; -condensation of the compact bone, which can be related to the load propagation patterns determined by the specific morphology of the implant; -organizing a strong trabecular structure that starts radially from the compact peri-implant bone; -the presence of a crystal bone wall at the level of the subepithelial conjunctiva, which can allow the junctional tropism of the formation of the sulcular epithelium.

The mature mineralized matrix, which has been described as appearing in dental and orthopedic clinical trials, is expected to ensure the mechanical stability of the implant even in the early stages of osseointegration (primary stability). In fact, due to the hydrophilic nature of the hybrid material, high levels of liquid are absorbed from the liquid external environment leading to significant swelling and an increase in the volume of the initially glassy hybrid material (Fig. 24).

The active biomechanical and biomechanical scaffold, therefore, fulfills two biomechanical functions, the first being strictly related to the stabilization of the prosthetic system after implantation (the prosthesis can be loaded early one hour after implantation), while the second function is the bone growth stimulus exercised the bony area around the implant.

\section{A Computed Tomography Scan Confirmed these Expectations}

Figure 25 shows the micro CT of these volumes.
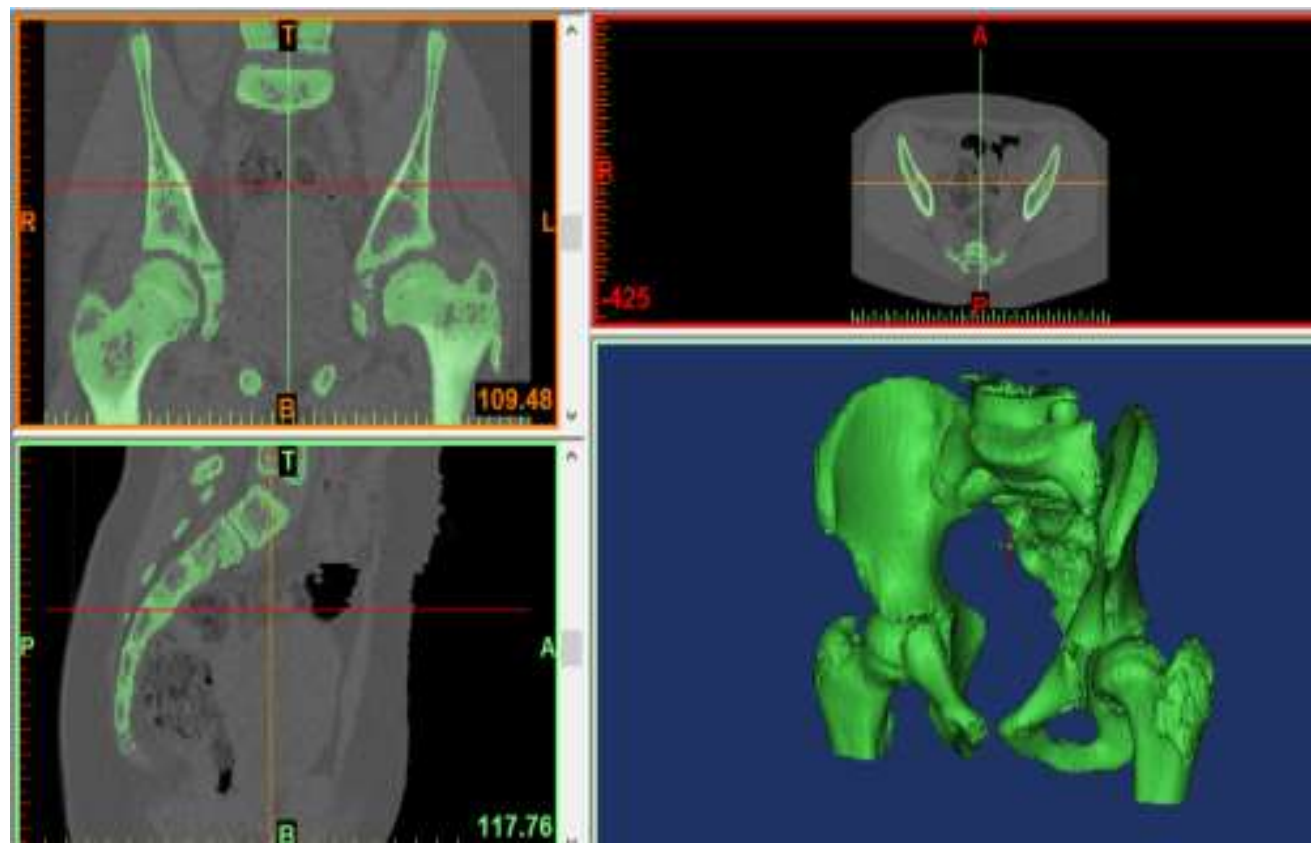

Fig. 17: Biofidel medical Image from Computerized Tomography (CT) of a patient pelvis: Point clouds raw data 
Relly Victoria Virgil Petrescu et al. / OnLine Journal of Biological Sciences 2021, 21 (2): 285.316 DOI: 10.3844/ojbsci.2021.285.316

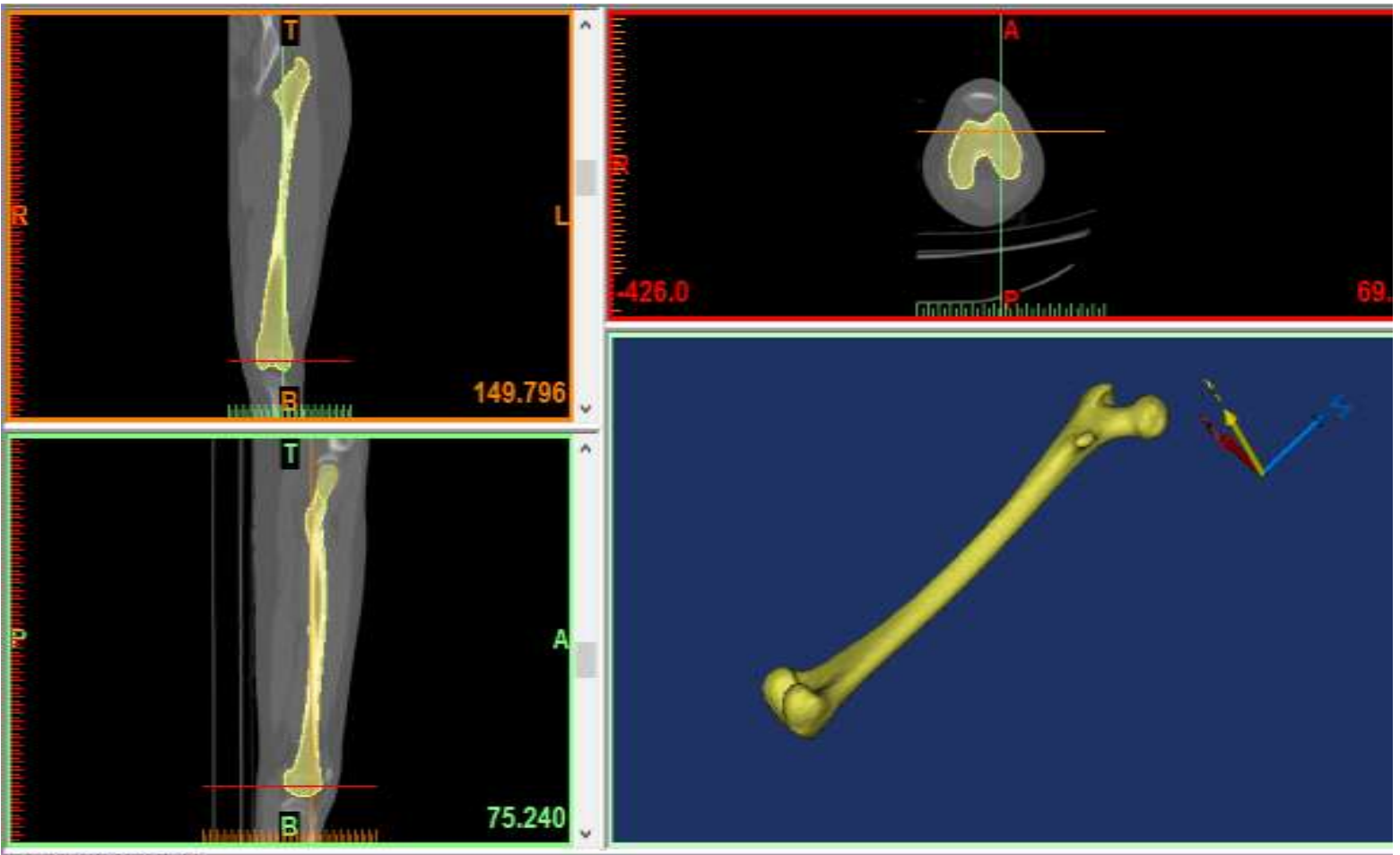

Fig. 18: CT segmentations and Biofidel 3D solid modelling: Transverse (upper right), medial (upper left), frontal (lower left) and bone solid reconstruction of a patient femur (lower right)

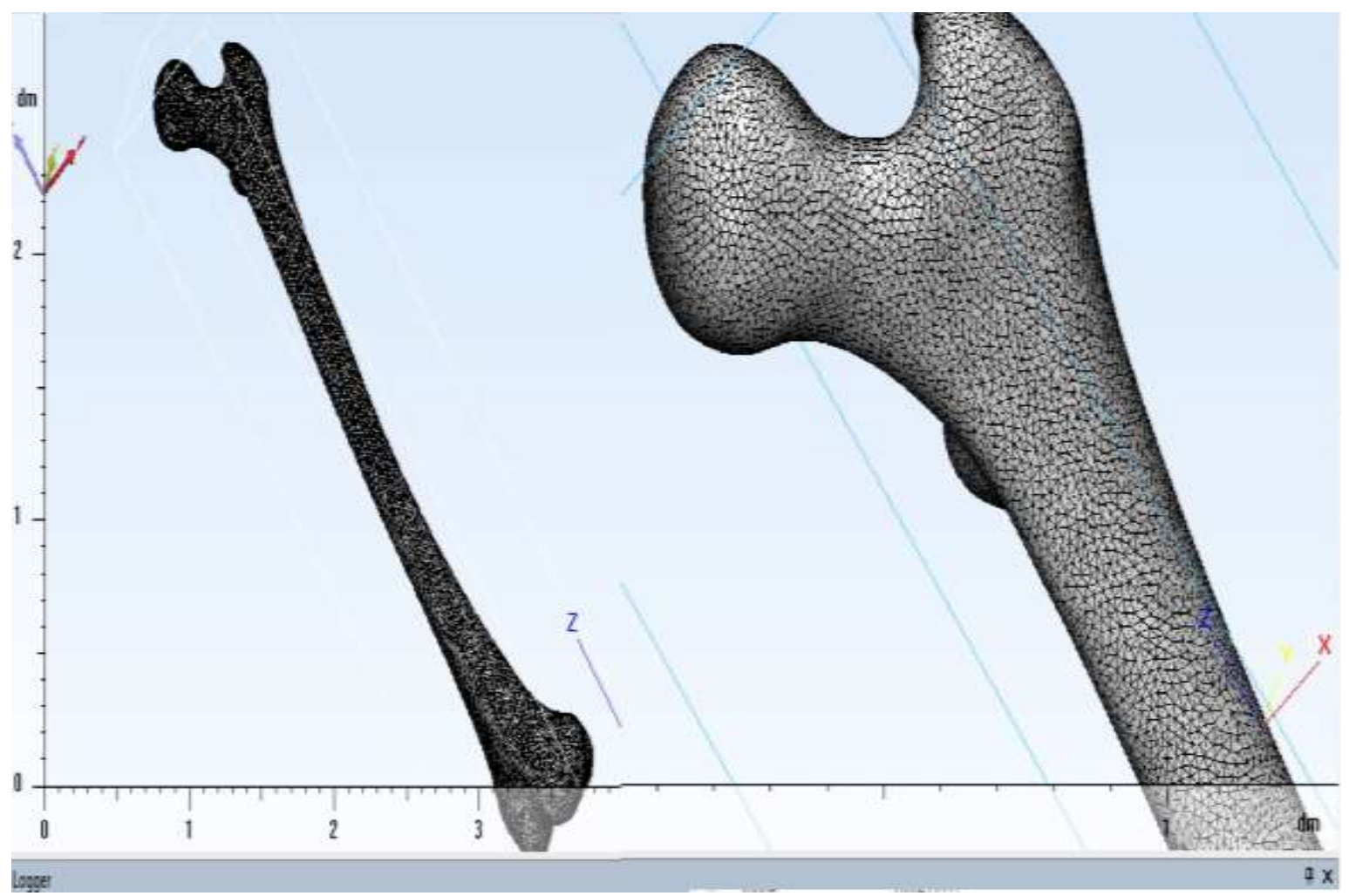

Fig. 19: Preliminary triangle surface meshing optimization of the biofidel patient femur model 
Relly Victoria Virgil Petrescu et al. / OnLine Journal of Biological Sciences 2021, 21 (2): 285.316 DOI: 10.3844/ojbsci.2021.285.316

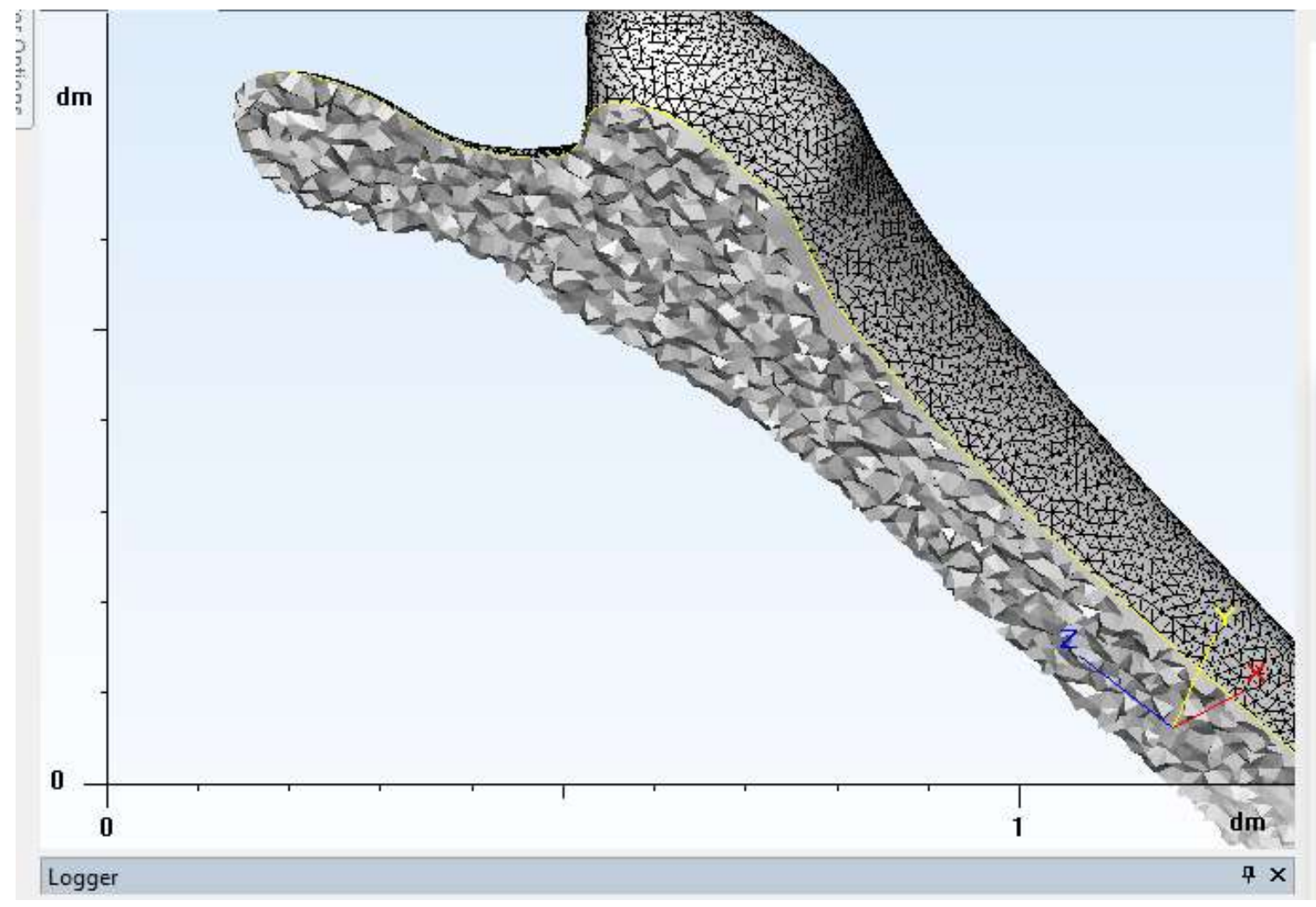

Fig. 20: Tethraedric 3D solid meshing optimization of the biofidel patient femur model (detail of the proximal end)
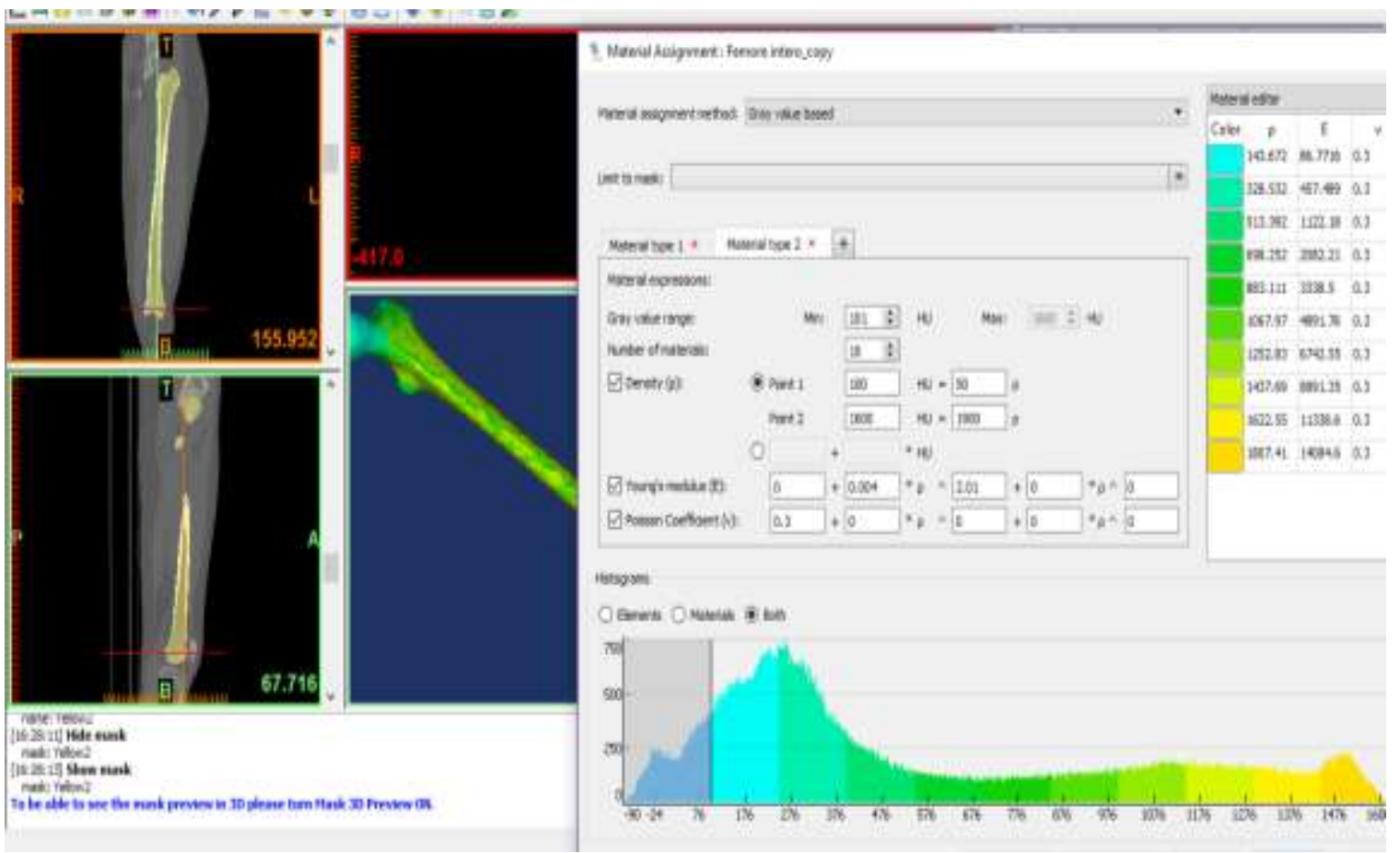

Fig. 21: Material properties definition associated to the patient femur cortical and trabecular bone densities (left) and material properties assignation to $\mathrm{HU}$ bone densities (right) 


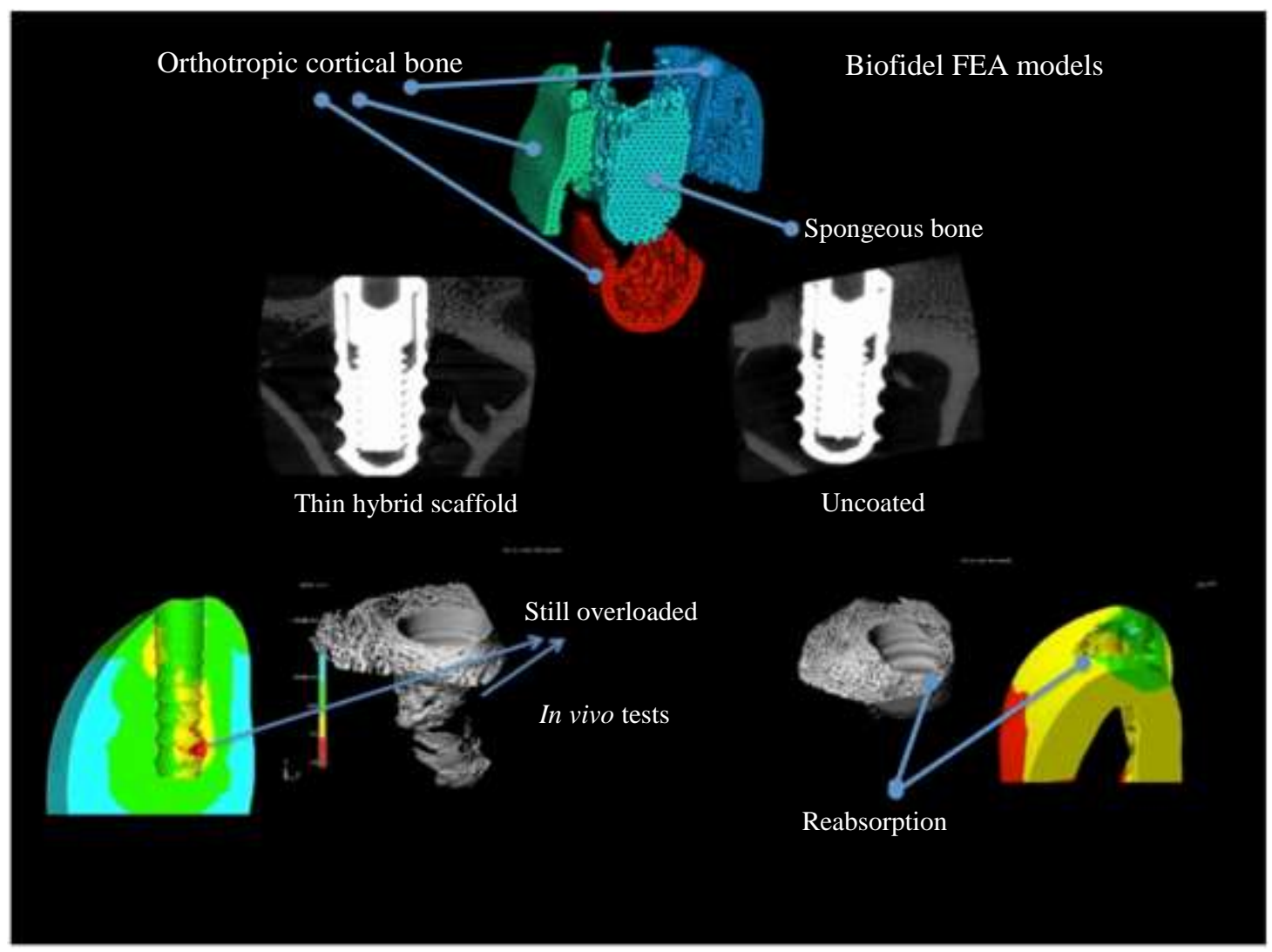

Fig. 22: In silico and in vivo validation for Osteoconduction of Titanium implants coated with a nanostructured hybrid osteoactive (left side) and without (right)

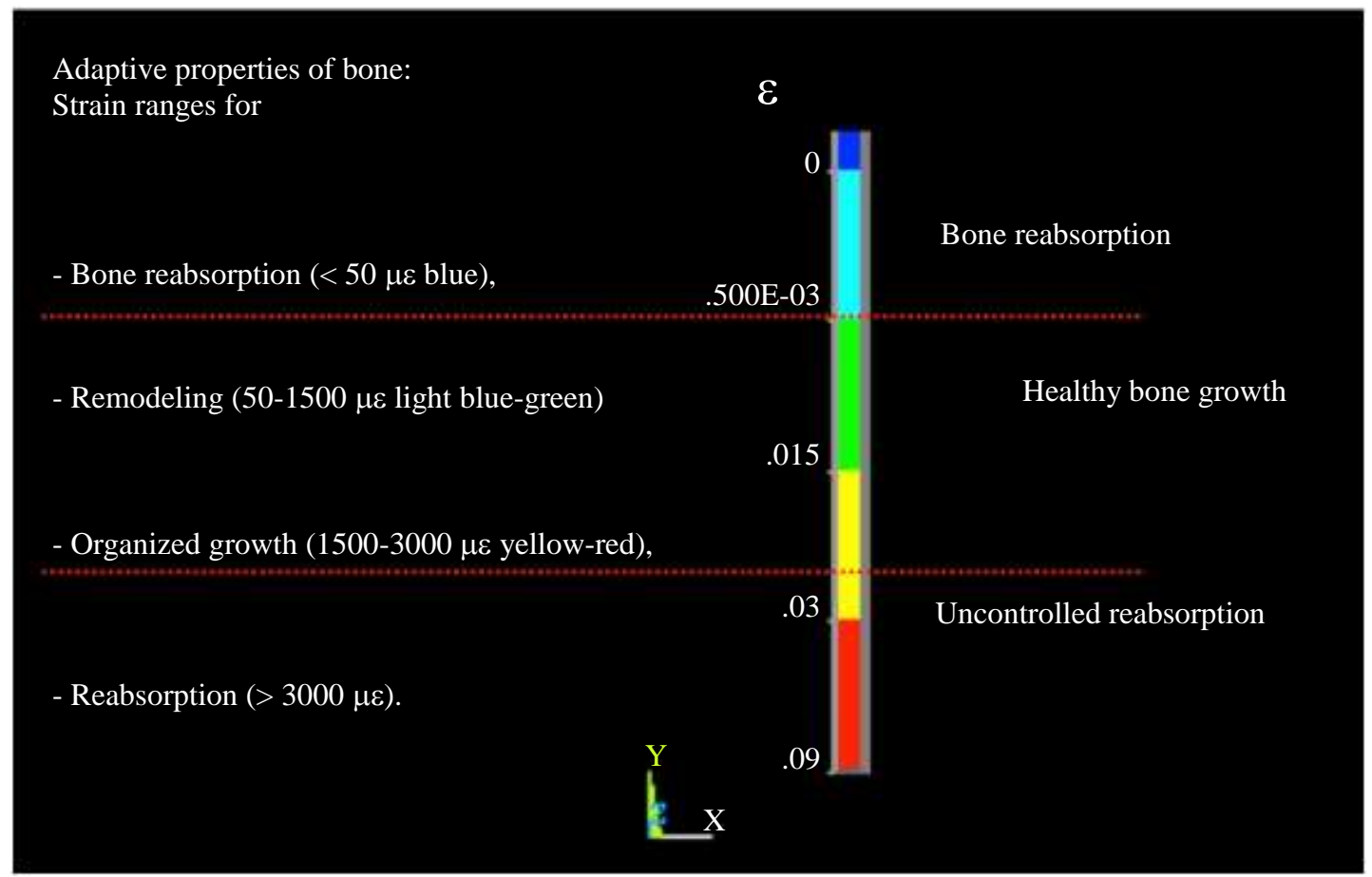

Fig. 23: Frost (1990) adaptive window of bone physiology: Structural adaptations to mechanical usage 
Two biomechanical functions:

- Implant fixture

- Bone growth stimulus

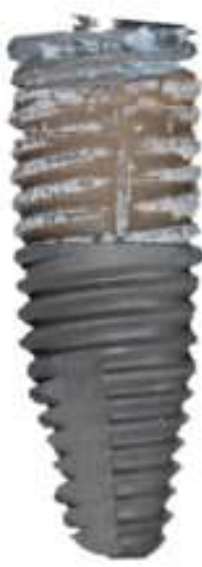

Dry glassy

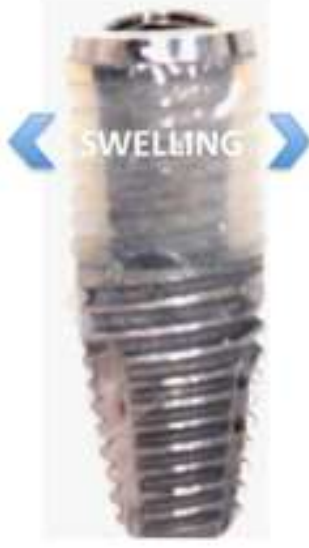

Swollen rubbery 13.5 linear

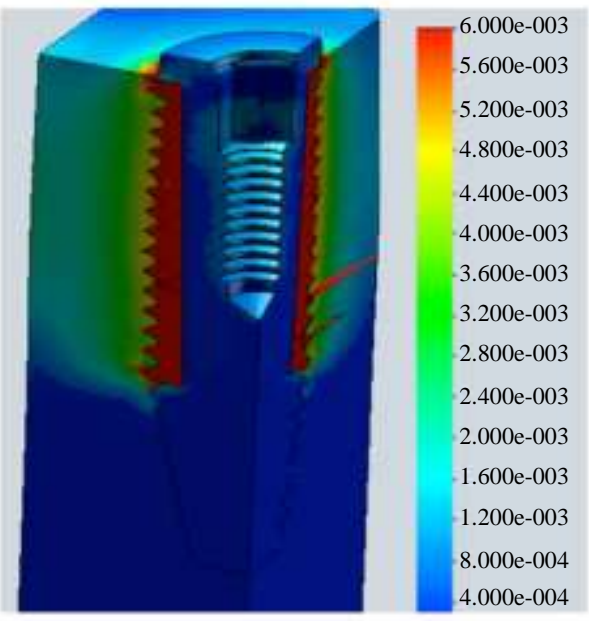

FEM simulation of swelling stresses

Fig. 24: Mechanisms of primary stability and osteoinduction improvements in Hybrid swellable scaffold modified Titanium implant. Glassy dry scaffold (left)

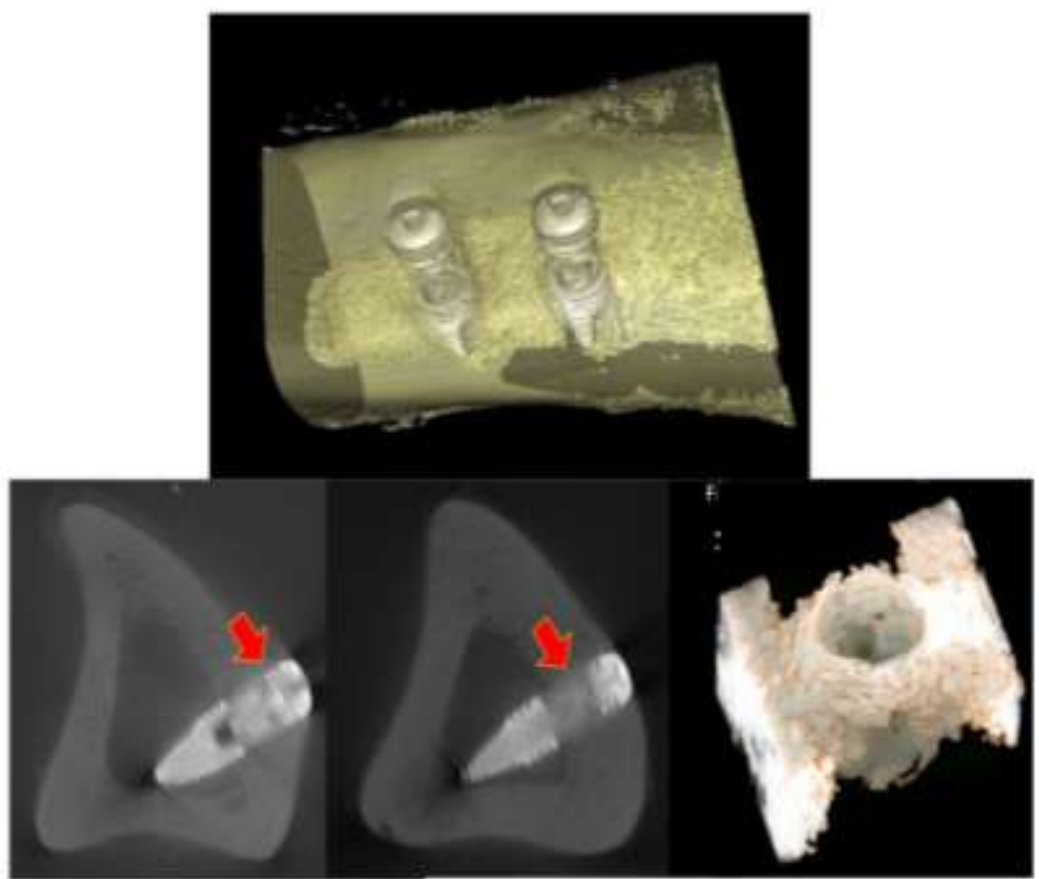

(a)

(b)

(c)

Fig. 25: The Bone to Implant Contact (BIC) and the relative bone density have shown similar characteristics at cortical (a) and medullar levels (b), Bone near to the implants shows similar characteristics (c) (Gramanzini et al., 2016)

At the top of the figure is reported the external volumetric reconstruction of the bone and implants, while at the bottom is the $3 \mathrm{D}$ reconstruction of the volume surrounding an implant.
Bone Implant Contact (BIC) and relative bone density showed similar characteristics at the cortical (a) and medullary (b) levels indicating good osseointegration of the implant with the original bone. 
The newly formed bone close to the implants has surprisingly similar characteristics to the previous one (c), indicating that a biomechanical stimulating effect of the swollen hybrid scaffold material.

\section{Discussion}

The body of an adult has 206 bones and a complex network of tendons, ligaments and cartilage that supports it. It has a number of vital functions, such as supporting, moving, protecting, producing red blood cells, storing calcium and balancing the endocrine system. In other words, without him, we would not be able to live.

The number of bones a man is born with is not the final one. Humans are born with about 300 bones, some of which fuse as the body develops. Males develop fully by the end of adolescence and females up to two years after the beginning of the menstrual cycle.

The skeletal system differs between men and women, mainly in the shape of the pelvis: In women, it must support pregnancy.

Although they become rigid and fragile outside the body, inside it is of course living tissue and the strength is different. It is fed by a network of blood cells from the circular system and nerves from the nervous system.

The bones have a hard, dense outer shell. Then comes the spongy bone, which is lighter and more flexible. Inside, in some bones, is the spinal cord, where new cells are constantly produced.

Teeth are considered to be part of the skeletal system, but they are not considered bones. They are made of dentin and enamel, the most resistant substances in the body.

The skeletal system has two major components: The axial skeleton and the appendicular skeleton. The axial one has 80 bones, being made up of the spine, the thoracic box and the skull. The appendicular has a total of 126 bones and consists of the rest, such as the limbs and pelvis.

The main tools for diagnosing diseases are those that can see beyond the soft tissue, such as the skin and organs. With the help of MRI, arthroscopy and radiographs, accurate diagnoses can be made, such as deformities or cancer.

The most common diseases are metabolic diseases, such as osteoporosis. It occurs mainly in the elderly and is manifested by loss of bone tissue. In other words, the bones lose calcium, become lighter, or even disappear. Osteomalacia, another common disease, is manifested by loss of bone hardness, resulting from vitamin D deficiency.

Arthritis is a group of over 100 inflammatory diseases that affect the joints and structures around them. It usually affects the most requested joints, such as the shoulders, knees, lumbar region, hips and carpels.

Scoliosis is also a common condition, which means bending in one part of the spine. The condition usually occurs in adolescence. In the United States alone, 2-3\% of the population suffers from this disease.
One of the rare but extremely dangerous conditions is bone cancer. It can even come from the bones or it can appear in the skeletal tissue from another tumor that is spreading in the body. In 2018, an estimated 1,590 people will die of bone cancer in the United States alone. This type of cancer has an occurrence of only $0.2 \%$. "Unfortunately, today this type of cancer is found especially in young patients aged $20-30$ years."

Leukemia is also associated with the skeletal system. This condition, which can be said to be blood cancer, has its origin in the bone marrow. Here, white blood cells multiply at an uncontrolled rate. This may be due primarily to a strong acute infection, but also to other prolonged or genetic stressors.

Bursitis is a condition that usually affects the shoulder and hip joints. It is caused by inflammation and fluid filling of the tissue.

The bone system is also susceptible to fractures.

The bones retain many toxic substances $(\mathrm{Hg}, \mathrm{Pb}, \mathrm{F})$ that accidentally enter the body and release them gradually, being then eliminated by the kidneys. In this way, the blood concentration of the toxicant does not increase too much and harmful effects on other organs are prevented.

In children, all the bones and in adults, the wide bones contain red, haematogenous marrow. In adults, the marrow in the central canal of the diaphysis of the long bones is yellow (adipose tissue with a reserve role) and in the elderly, it is gray, almost non-functional.

Bones also play an essential role in the metabolism of calcium, phosphorus and electrolytes, maintaining physiological balance in the body. Bones are the main reservoir of mineral substances in the body.

The roles of the skeletal system in the human body are therefore extremely important. It must be understood from the start that the skeletal system is not just a shield to defend the internal organs and a skeleton to support these internal organs, which was difficult anyway being dynamic support while walking or running. The skeletal system is thought of as an organ with multiple roles in the human body. First of all, it is the one that produces and maintains all the basic cells of the body, including plasma. Blood is the body's vital fluid that carries food to the basic cells of the whole body constantly, along with energy, energy and nutrients, plus oxygen. He is also the one who returns the toxins from the basic cells of the body back to the organs that will throw them out of the body, the products eliminated by the cells from nutrition and oxygenation will be returned through the blood to the kidneys, liver, interstitial fluid, lungs, for processing and elimination. The blood also carries extremely important mineral salts to the cells of the whole body. All the blood is manufactured and regenerated permanently in the bones, in their bone marrow, mostly in the spinal cord and in the large, wide bones. In children, almost all the bones participate in this process, in adults they diminish and in the elderly, the bones that 
produce the bone marrow, which is responsible for the production of blood, the vital plasma for the body, almost disappear. Hence the first cause of aging of the human body, with the decrease in the number of bone makers of plasma, with age, which leads in time to insufficiency of a new plasma clean, oxygenated, nourished, energetic. The human bone marrow is also the one that produces a large number of red blood cells, erythrocytes, cells responsible for blood clotting in case of platelet injury and most white blood cells for the body's immune defense leukocytes, which are extremely diverse and very many. categories and forms, today we know only a few of the existing types, otherwise, they are constantly diversifying and depending on the new defense needs of the body against new intruders who can also be more diverse, especially since the new virus strains.

Today the problem of new leukocytes that can fight effectively against new strains of mutant viruses is a serious even acute one, so we should all think of ways to get as much immunization as possible from the human body a natural dynamic, not through vaccinations, an enhanced immunity of the body through various classical procedures and procedures given and new, modern.

On the other hand, it must be thought that the bone marrow also produces the stem cells so desired and necessary by the human body because it adapts quickly to all areas of the body, to any organ, or part of it, helping to restore it when necessary after injuries, injuries, illnesses, i.e., when there is an acute crisis at a certain level of the body, except the brain, where the cells specialized in those areas cannot multiply quickly and well enough, stem cells adapt quickly to any area and properly restore the affected area in a timely manner, which helps a lot to keep the whole body young at the correct maintenance at almost any age, as long as the body has enough bone marrow, enough healthy bones to produce cells through their marrow plasma and the necessary stem cells. In addition, all will always be transported quickly to where they are needed due to the fresh plasma produced in sufficient quantities by the bone marrow of young, wide bones plus the spinal cord. Because of this, when the bones degrade from old age, disease, or injury, or due to an inadequate lifestyle, severe imbalances occur throughout the body that leads over time to disease, insufficiency, suffering, acute and then chronic, which not treated properly and in time will eventually lead to the death of the body.

We were talking about the fact that the skeletal system not only maintains and defends the internal organs but also has the role of producing plasma and its cells plus stem cells of vital importance for the whole body, but also the bones are those that have the essential role of creating a reserve of plasma, saline, nutrients, being at the same time a kind of thermos of the human body in which large reserves of vital fluids are stored, but also from those from which plasma is manufactured. So the bones keep the saltwater with the nutrients from which the plasma will also be made in them, but at the same time, they maintain a blood reserve, which can be pumped at any time with power and in sufficient quantities wherever it will be needed throughout the body. A reserve of blood is also made by the liver, lungs, kidneys, one of water, the interstitial fluid, but both saltwater with nutrients and freshly made blood are kept fresh even in the living thermos made by the very bones of the human body. For this reason, when there is great damage to the bones, for various reasons, there is a decrease in the supply of vital fluids, which leads to a decrease in the amount of useful plasma that can be produced and used and to possible disorders of the body. If the bones are not repaired in time they will affect in the long run or permanently the production of blood and its reserve in the body and the functioning of the whole body will become deficient and slowly the condition of the body will deteriorate and it will age. This will also result in the death of the body sooner or later.

Let us understand from here that the nutritional and respiratory processes of the whole organism depend directly and indirectly on the permanent amount of blood but also on the quality of the plasma at any moment, as well as on the body's basic reserve of the vital fluids, i.e., all these essential physiological processes are dependent. directly from the normal and healthy bone system. The rupture of an important bone will directly and immediately affect all these important processes and in the long run, the consequences can even become serious. Long-lasting bone disease or a serious injury to important bones or the spine could be even more devastating if this injury is not repaired properly and quickly. For this reason, this study tries to present various original methods to repair fractured bones correctly and in a timely manner, the paper representing a review of several efforts made in time in this field by its authors.

The energy processes inside each basic human cell are based on the energy of ATP-type molecular chains produced by the mitochondria in that cell. We remind you that mitochondria are practically minicells in cells that have various roles within the host cell, including control of feeding and energization, control of redox reduction, control of division for multiplication, selection of very sick, old, cancerous cells for the destruction process of mitochondria on standby or on the function of cells destined for their destruction, or self-destruction because they are too sick and can no longer heal and they are no longer allowed to divide so as not to give birth to inappropriate new cells. Within a human cell, there may be as many or as many mitochondrial cells as needed in that cell for more or less energy. For example, muscle cells, especially the heart, but also the neurons of the brain need more energy, so in the tissues of the muscles, heart and brain, there will be several mitochondria per cell, even 1000 mitochondria in a single human cell, in order to produce as many ATP-type molecular energy 
chains as donors of basic energy for the body, knowing that the extra energy obtained by the body from sugars, fats, etc., is not exactly clean and healthy.

Maybe here we should make a parenthesis, a clarification, that one of the essential organs, the human brain, its neuron, i.e., its basic cell, cannot be restored too easily and for a long time it was thought that the neurons initially in the huge reserve do not they can recover, but more recently it has been found that their reproduction time is very long, from 60 to 120 years, while other cells recover much faster. For example, the skin recovers completely in no more than 30 days, the ligament muscles recover completely in two to three weeks, the anal area recovers in just a few hours up to $24 \mathrm{~h}$, the eye cells can recover differentially from hours to weeks and so on.

It is not yet known exactly the mechanism by which the various cell types reproduce and how stem cells adapt anywhere, but it may be possible in the future to conduct studies and research to demonstrate the role of all factors that can help restore faster any area of the human body and even the brain, including stem cells.

Given the importance of the bone system as a whole and the fact that it is the one that controls the vitality of the whole body, the separate study of the various bones and how they can be repaired in case of injury with a fracture or even rupture, is very important because partial repair or blockage of the natural structure of the bones will lead in time to a bony area that will no longer give the necessary yield in storage and manufacture of vital fluids of the body and the affected area will degenerate and be damaged and the rest of the bones will difficult to be able to produce its part that it did before. From such degradations, the body can suffer a lot and over time there will be a malfunction, slow vital processes, incomplete, poor elimination of toxins from the body, with frequent poisoning and premature aging of the whole body.

The field of interdisciplinary research of materials for biomedical applications is strongly based on the study of bone tissue repair.

Bone is considered a hybrid biological material composed of an organic component, collagen and an inorganic component of nanocrystalline hydroxyapatite. Both phases are integrated at the nanoscale level so that morphological and physical variables such as crystallite size, nanofiber orientation, short-term order between the two components determine its nanostructural characteristics and therefore functional and mechanical properties. of different bone types (Frost, 1964; 1990; 2004).

Based on bone regeneration criteria, we have developed new bioactive biomaterials. These materials are expected to promote bone formation, favoring the proliferation and differentiation of osteoblasts (Schiraldi et al., 2004).

The use of nanostructured materials similar to that of natural bone tissue is one of the most promising options in bone healing. Nanotechnologies for the implementation of hybrid organic-inorganic materials offer excellent chances for improving the performance of existing conventional bone implants.

This research evaluates the progress made in nano-silicate-polymer hybrids for bone repair, as well as the chemical procedures that allow the control of the nanostructure of the material.

The objective of the paper is inherent in the following scientific fields:

- Biomechanics and Biofidelity of human bone modeling

- Biomimetics: Nanotechnologies in medicine for nature-inspired materials

- Bioactive scaffolds that promote osseointegration into porous structural nanocomposites and hybrid matrices

- $\quad$ Biofidelity is advancing

Recent studies on the mandible (Apicella et al., 2010; Aversa et al., 2009; 2016a; 2016b) and FEM modeling of teeth (Apicella et al., 2011; Davide et al., 2015) suggest that biomechanical investigation of bones could be applied with Successful orthopedics to provide a means to predict the clinical outcomes of implant-based restoration procedures.

Knowledge of the mechanical and adaptive characteristics of bone is a critical issue in the design of new biomimetic prostheses to replace a bone with minimal biological and biomechanical invasiveness.

Biomimetics is the science that investigates such problems and can be considered the natural junction between biology and engineering. This convergence of competence allows the development of biological principles and models needed to produce bio-inspired materials that can be used for the complete design of tissues and prosthetic systems.

New generations of concepts could be generated by the conscious investigation of biomimetics, which can provide the clinical tools to restore the structural, biomechanical and aesthetic integrity of bone functions.

Recent technological advances in cellular and molecular biology and materials engineering science (nanotechnology) have established that biomimetics and tissue engineering appear to contribute to improving the complete integration of restoration and prosthetic implants (Aversa et al., 2009; 2016a; Perillo et al., 2010; Annunziata et al., 2006; Apicella et al., 2010).

Since the last century, many parts of our body have been replaced with artificial prostheses. The materials used for these devices have been chosen so as not to produce adverse responses in contact with human body tissues and physiological fluids.

The criteria for choosing a specific biomaterial were related to its biocompatibility and functionality, which 
could be directly associated with bone/implant interface interactions at the nanomedical level. It was not until the $1990 \mathrm{~s}$ that the study of these interface effects was enhanced by the use of thin nanometer coatings and surface changes.

Then there was a great commercial interest in the orthopedic market to adopt new modified implants with surface nano treatment that promote hard and soft tissue engineering (Annunziata et al., 2008; Cameron, 1986).

New classes of biomaterials

There are several ways in which living tissues can react to the synthetic materials of implants, but they are essentially limited to their responses to the interface material.

Three main terms could describe the behavior of biomaterials, as defined by Jones and Clare (2012); Hutmacher (2000) and Hoppe et al. (2011).

Namely, tissue responses are divided into:

\section{- Bioinert \\ - Bioresorbable \\ - Bioactive}

Another classification of ceramic-based biomaterials can be made according to their reactivity to physiological fluid:

- $\quad$ Bioinert, such as alumina for dental application)

- Bioactive materials, such as hydroxyapatite used as a coating on metal implants

- Active on the surface, such as organic glasses or A-W glasses

- Bio-resorbed, it is tri-calcium phosphate

Further improvement of these material properties can be achieved using nanostructured bioceramics that can be used as interactive materials, helping the natural tendency of tissues to heal by promoting tissue regeneration and restoring physiological functions (Schiraldi et al., 2004; Mano et al., 2004; Morales-Hernandez et al., 2012; Mourino et al., 2012).

This approach was investigated in this study to develop a new generation of nano-structured bioceramic-polymeric hybrids that can be used in a wider range of medical applications.

Porosity is one of the keys to the success of these materials and is increasingly adopted when natural bone growth and strong implant stability are required.

\section{Tissue Engineering New Perspectives}

For several years, tissue engineering has benefited from the combined use of living stem cells seeded in three-dimensional ceramic scaffolding. This strategy is completed to provide healthy cells directly to the affected site (Bonfield et al., 1981; Hench, 1993; Hench and Polak, 2002; Hench and Thompson, 2010).
By combining the traditional bio-ceramic implant, with the already assimilated knowledge about the growth and differentiation of stem cells into an osteogenic one, practical and productive clinical strategies have been developed.

Stem cells cultured in ceramic nano-biocomposites could be adopted for extensive bone repair, with excellent prospects for good functional recovery and integration of hybrid bone scaffolds.

Synthetic Hydroxyapatite (Hap) has been described in the literature as an attractive material for bone implants (Kim et al., 2004; Morales-Hernandez et al., 2012).

Since its adoption, the most widely used and simplest production method for synthetic HAp is the solid-state reaction between calcium and phosphate ions, leading to the formation of powdered compounds that can be sintered and cooled to a high temperature to form a structure compact polycrystalline (Julien et al., 2007).

HAp bioactivity is governed by processing parameters, such as the initial compounds, the size of the crystal granules, their purity and the ratio between calcium and phosphorus atoms. In particular, nanocrystals showed improved bioactivity due to the increased surface area. The use of hydroxyapatite nanoparticles has been proposed as a valid solution for the reinforcement of low-strength polymer scaffolding.

By using nanoparticulate HAp, new classes of implants, biocompatible coatings and high-strength nanocomposites can be developed (Gorustovich et al., 2010).

\section{Biomimetics}

A characteristic feature of several hard natural hybrid materials, such as bone, sea urchin tooth, mother-ofpearl, is the strong nanometric-scale interaction between inorganic and organic phases. This feature allows the organic phase to act at the nanomedical level as an extremely energy dissipating plastic network that inhibits crack propagation (high resistance); In situ synthesis techniques have been adopted to mimic natural processes. In particular, the precipitation of hydroxyapatite (or another crystalline compound) in a polymeric matrix has been considered a viable way to produce biomimetic composites.

\section{Organic-Inorganic Hybrid Biomaterials}

An approach to the development of bioinspired material, given the formation of the organic-inorganic selfassembled hybrid, will favor the use of hybrids in biomedical applications. The high versatility of these hybrids offers the main functional and structural advantages that lead to the possibility of customizing materials in terms of shape and chemical and physical properties.

\section{Bioengineering and Bioactive Scaffolding}

For bioengineering with micro and nanomaterials, nanotechnology is increasingly adopted for emerging 
applications such as coatings or three-dimensional scaffolding (tecto) (Aversa et al., 2016a; Karageorgiou and Kaplan 2005; Sorrentino et al., 2007). Decisively, micro and nano-technologies show the potential to be used to manufacture advanced models for fundamental studies, such as commissioned tissue engineering structures or bio-molecular devices.

The ideal material for bone scaffolding has always been a hot topic for research. An ideal scaffold should provide a sufficiently rigid but strong network to temporarily replace damaged bone.

Highly bioactive amorphous fumed silica nanocomposites have been synthesized in our laboratory. A new class of hybrid polymer-ceramic materials that mimic the mechanical behavior of bone has been used as a potential scaffolding material.

The result of these self-assembled nanostructured composites was micro-foamed and tested as a new perimeter scaffold that can accommodate osteoblast growth factors or stem cells to differentiate osteoblasts.

\section{Biofidelity Models and Fem Analysis}

Understanding the biological mechanisms of healthy dynamic bone growth is an iterative process between biology and engineering. During this process, the knowledge that reverse engineering of a biological system can bring can have positive feedback back in biology, allowing a more complete and more secure understanding of the potential path of further developments in applied medical engineering.

The most important question is how the clinician's interference with biological systems can be optimized to improve treatment modalities so that the effectiveness of the treatment increases and leads to a more stable result.

The use of newly developed combined diagnostic and engineering tools, such as those used in our research (e.g., maxillofacial MRI segmentation or CT segmentation and solid CAD reconstruction) can detail the anatomy of hard and soft textures in an extremely precise way smaller standard deviations. Therefore, the integration of biological knowledge and clinical possibilities is essential. A more reliable and biofidel model begins with biomechanical modeling of bones, ligaments and alveolar bone, using finite element analysis to gain insight into the biological response to changing biomechanical circumstances.

Because current tests and numerical methods are closely linked, an appropriate methodological approach is to combine in vitro and in vivo experiments with computer simulations (in silico). There are, however, a number of incentives involved in creating the mathematical model and achieving it. The simultaneous interaction of several variables that influence the prosthetic system was investigated by simulation in the mathematical modeling of finite elements.
Finite Element Analysis (FEA) involves dividing a geometric pattern into a finite number of elements, each with specific mechanical properties. The variables to be investigated are guessed with mathematical functions. Specific math programs assess the distribution of stresses and strains in response to changing load conditions.

A complete assessment of the mechanical behavior of a solid or protected biological structure is feasible, even in inhomogeneous bodies. When properly validated by in vivo or in vitro tests, finite element analysis is useful in defining optimal restorative design criteria and material selection criteria, while allowing the prognosis a potential fracture under given conditions.

\section{Conclusion}

The innovative aspects of our work are that, unlike currently used prostheses, which are only intended to replace a damaged hip joint, the proposed prosthetic prostheses can be completely biomimetic because they mimic the distribution of biological stress stimulates tissue regeneration physiology.

The average lifespan of a prosthesis today is about $10 / 15$ years, while the new "biomimetic prosthesis" will have a longer life expectancy, which can be estimated over $20 / 25$ years.

This is very important, as the average life expectancy increases progressively and, as a result, the number of orthopedic surgeries and the costs of social and health care increase.

The design and manufacture of customized structured structures of innovative biomimetic systems that could be better integrated with the physiological biomechanics of the femur in which they are implanted are possible through the correct use of these biophilic models.

The aim of the study is to create added value by combining existing research with biomechanical results with the innovative prosthetic design and structural simulation activities.

The transfer of results in academic and industrial research on biomechanics and clinical trials leads to an acceleration of innovation and profit while improving the quality of life of patients with prostheses.

This study identifies a set of design criteria to stimulate the potential to enable new health therapies to contribute to personalized healthcare, create and improve the technology base and increase resource efficiency in the context of industrial and manufacturing processes. The new type of biomimetic implants can find applications in the knee, ankle, hip, shoulder and orthopedic spine.

Another field of application of the product is surgical oncology to support and facilitate bone regeneration, resulting in massive losses due to primary and metastatic interventions to remove the tumor.

The prosthetic system could allow better functional recovery by promoting bone recreation to ensure good 
maintenance, even if it will have an impact on the quality of life of the individual patient severely compromised by the underlying oncological pathology.

The concept of combining a supporting metal structure (to guarantee load resistance) a biomimetic scheme (which promotes regeneration) applies to all areas of surgical treatment that involve the removal of bones and requires the regeneration of regenerated tissue.

It is necessary to develop new technologies in the field of biomaterials, in order to obtain bone scaffolds and substitutes that could play a fundamental role in bone regeneration. Bone scaffolding must have special intrinsic characteristics to function as a real bone substitute that satisfies biological, mechanical and geometric constraints. Such features include:

- Biological requirements-the calculated scaffolds must allow cell adhesion and homogeneous distribution, growth of regenerative tissue and help the passage of nutrients and chemical signals. This achievement was achieved by controlling the porosity of the scaffold

- Mechanical requirements-estimated scaffolds must retain the mechanical and strength properties that allow osteoblast colonies to experience controlled physiological and bioactive deformities. This was achieved by the corresponding modification of the ceramic-hybrid polymer compositional ratio (in our case, $10 \%$ by volume of amorphous nano-silica)

The combined clinical observation of traditional implant behavior will be used to validate the biofidelity of FEM models, while the comparison between in vitro and computer-assisted simulation of osteoblast colony growth can then allow us to explore many new ideas in modeling, design and production we are nanostructured scaffolds with improved functionality and improved interaction with cells; this becomes especially useful in the design and direct manufacture of complex bone scaffolding.

The complex biomechanics and morphologies of the femur proximal epiphysis are presented. The nature and fine morphology of the femur head and its structural behavior have been investigated. Isotropic and orthotropic trabecular structures have been associated with oriented compression and tensioned areas of the femur head FEM models. These isotropic/orthotropic trabecular morphologies and their allocations govern the stress and strain distribution in the overall proximal femur region.

Finite element models of the femur biofidel were developed using a specific combination of segmentation with computed tomography and solid modeling tools capable of representing bone physiology and structural behavior. This biofidel Finite Element (FEM) model is used to evaluate the change in the physiological distribution of stress in the femoral prosthesis and to evaluate the new design criteria for biopsy. The use of femur proper biofidel modeling while enabling the explanation of physiological stress distribution elucidates the critical mechanical role of the trabecular bone that should be accounted for in the design new innovative more "biologic" prosthetic system. Biomimetics, biomechanics and tissue engineering are three multidisciplinary fields that have been considered in this research to achieve the goal of improving the reliability of prosthetic implants. The authors took these studies to gather the untapped potential of such advanced materials and design technologies by developing finite models of Biofidel elements capable of correctly mimicking the biomechanical behavior of the femur.

\section{Acknowledgement}

This text was acknowledged and appreciated by Assoc. Pro. Taher M. Abu-Lebdeh, North Carolina A and T State Univesity, United States, Muftah H. El-Naas PhD MCIC FICCE QAFCO Chair Professor in Chemical Process Engineering Gas Processing Center College of Engineering Qatar University, Professor Guanying Chen Harbin Institute of Technology \& SUNY Buffalo China.

\section{Funding Information}

This research has been funded by Italian Ministry of University and Research project FIRB Future in Research 2008 project RBFR08T83J.

\section{Author's Contributions}

All the authors contributed equally to prepare, develop and carry out this manuscript.

\section{Ethics}

This article is original and contains unpublished material. Authors declare that are not ethical issues and no conflict of interest that may arise after the publication of this manuscript.

\section{References}

Abdul-Razzak, K. K., Alzoubi, K. H., Abdo, S. A., \& Hananeh, W. M. (2012). High-dose vitamin C: Does it exacerbate the effect of psychosocial stress on liver? Biochemical and histological study. Experimental and Toxicologic Pathology, 64(4), 367-371. https://doi.org/10.1016/j.etp.2010.09.011

Annunziata, M., Aversa, R., Apicella, A., Annunziata, A., Apicella, D., Buonaiuto, C., \& Guida, L. (2006). In vitro biological response to a light-cured composite when used for cementation of composite inlays. Dental Materials, 22(12), 1081-1085. https://doi.org/10.1016/j.dental.2005.08.009 
Annunziata, M., Guida, L., Perillo, L., Aversa, R., Passaro, I., \& Oliva, A. (2008). Biological response of human bone marrow stromal cells to sandblasted titanium nitride-coated implant surfaces. Journal of Materials Science: Materials in Medicine, 19(12), 3585-3591. https://doi.org/10.1007/s10856-008-3514-2

Apicella, D., Aversa, R., Ferro, F., Ianniello, D., \& Apicella, A. (2010). The importance of cortical bone orthotropicity, maximum stiffness direction and thickness on the reliability of mandible numerical models. Journal of Biomedical Materials Research Part B: Applied Biomaterials: An Official Journal of The Society for Biomaterials, The Japanese Society for Biomaterials and The Australian Society for Biomaterials and the Korean Society for Biomaterials, 93(1), 150-163. https://doi.org/10.1002/jbm.b.31569

Apicella, D., Veltri, M., Balleri, P., Apicella, A., \& Ferrari, M. (2011). Influence of abutment material on the fracture strength and failure modes of abutment-fixture assemblies when loaded in a bio-faithful simulation. Clinical Oral Implants Research, 22(2), 182-188. https://doi.org/10.1111/j.1600-0501.2010.01979.x

Ashman, R. B., \& Rho, J. Y. (1988). Elastic modulus of trabecular bone material. Journal of Biomechanics, 21(3), 177-181. https://doi.org/10.1016/0021-9290(88)90167-4

Ashman, R. B., Cowin, S. C., Van Buskirk, W. C., \& Rice, J. C. (1984). A continuous wave technique for the measurement of the elastic properties of cortical bone. Journal of Biomechanics, 17(5), 349-361. https://doi.org/10.1016/0021-9290(84)90029-0

Aversa, R., Apicella, D., Perillo, L., Sorrentino, R., Zarone, F., Ferrari, M., \& Apicella, A. (2009). Non-linear elastic three-dimensional finite element analysis on the effect of endocrown material rigidity on alveolar bone remodeling process. Dental Materials, 25, 678-690. https://doi.org/10.1016/j.dental.2008.10.015

Aversa, R., Buzea, E. M., Petrescu, R. V., Apicella, A., Neacsa, M., \& Petrescu, F. I. (2016e). Present a mechatronic system having able to determine the concentration of carotenoids. American Journal of Engineering and Applied Sciences, 9(4), 1106-1111. https://doi.org/10.3844/ajeassp.2016.1106.1111

Aversa, R., Parcesepe, D., Petrescu, R. V., Chen, G., Petrescu, F. I., Tamburrino, F., \& Apicella, A. (2016b). Glassy amorphous metal injection molded induced morphological defects. American Journal of Applied Sciences, 13(12).

https://doi.org/10.3844/ajassp.2016.1476.1482

Aversa, R., Perrotta, V., Petrescu, R. V., Misiano, C., Petrescu, F. I. T., \& Apicella, A. (2016g). From structural colors to super-hydrophobicity and achromatic transparent protective coatings: Ion plating plasma assisted $\mathrm{TiO} 2$ and $\mathrm{SiO} 2$ nano-film deposition. American Journal of Engineering and Applied Sciences, 9(4), 1037-1045. https://doi.org/10.3844/ajeassp.2016.1037.1045
Aversa, R., Petrescu, F. I., Petrescu, R. V., \& Apicella, A. (2016a). Biomimetic finite element analysis bone modeling for customized hybrid biological prostheses development. American Journal of Applied Sciences, 13(11), 1060-1067. https://doi.org/10.3844/ajassp.2016.1060.1067

Aversa, R., Petrescu, F. I., Petrescu, R. V., \& Apicella, A. (20160). Flexible stem trabecular prostheses. American Journal of Engineering and Applied Sciences, 9(4). https://doi.org/10.3844/ajeassp.2016.1213.1221

Aversa, R., Petrescu, R. V. V., Apicella, A., \& Petrescu, F. I. T. (2020a). Trabecular prostheses. Independent Journal of Management \& Production, 11(4), 1223-1246. https://doi.org/10.14807/ijmp.v11i4.989

Aversa, R., Petrescu, R. V. V., Apicella, A., \& Petrescu, F. I. T. (2020b). Biologically structured materials. Independent Journal of Management \& Production, 11, 1119-1139. https://doi.org/10.14807/ijmp.v11i4.950

Aversa, R., Petrescu, R. V., Apicella, A., \& Petrescu, F. I. (2016i). Mitochondria are naturally micro robots-a review. American Journal of Engineering and Applied Sciences, 9(4).

https://doi.org/10.3844/ajeassp.2016.991.1002

Aversa, R., Petrescu, R. V., Apicella, A., \& Petrescu, F. I. (2016j). We are addicted to vitamins C and EA review. American Journal of Engineering and Applied Sciences, 9(4), 1003-1018.

https://doi.org/10.3844/ajeassp.2016.1003.1018

Aversa, R., Petrescu, R. V., Apicella, A., \& Petrescu, F. I. (2016k). Physiologic human fluids and swelling behavior of hydrophilic biocompatible hybrid ceramo-polymeric materials. American Journal of Engineering and Applied Sciences, 9(4), 962-972. https://doi.org/10.3844/ajeassp.2016.962.972

Aversa, R., Petrescu, R. V., Apicella, A., \& Petrescu, F. I. (20161). One can slow down the aging through antioxidants. American Journal of Engineering and Applied Sciences, 9(4).

https://doi.org/10.3844/ajeassp.2016.1112.1126

Aversa, R., Petrescu, R. V., Apicella, A., \& Petrescu, F. I. (2016m). About homeopathy or $\ll$ Similia similibus curentur $\gg$. American Journal of Engineering and Applied Sciences, 9(4). https://doi.org/10.3844/ajeassp.2016.1164.1172

Aversa, R., Petrescu, R. V., Apicella, A., \& Petrescu, F. I. (2016n). The basic elements of life's. American Journal of Engineering and Applied Sciences, 9(4), 1189-1197. https://doi.org/10.3844/ajeassp.2016.1189.1197

Aversa, R., Petrescu, R. V., Apicella, A., \& Petrescu, F. I. (2017a). Modern transportation and photovoltaic energy for urban ecotourism. Transylvanian Review of Administrative Sciences, Special, (2017), 5-20. https://doi.org/10.24193/tras.SI2017.1

Aversa, R., Petrescu, R. V., Apicella, A., \& Petrescu, F. I. (2017b). Under water. Online Journal of Biological Sciences, 17(2), 70-87. https://doi.org/10.3844/ojbsci.2017.70.87 
Aversa, R., Petrescu, R. V., Petrescu, F. I. T., Perrotta, V., Apicella, D., \& Apicella, A. (2021). Biomechanically Tunable Nano-Silica/P-HEMA Structural Hydrogels for Bone Scaffolding. Bioengineering, 8(4), 45. https://doi.org/10.3390/bioengineering8040045

Aversa, R., Petrescu, R. V., Petrescu, F. I., \& Apicella, A. (2016c). Smart-factory: Optimization and process control of composite centrifuged pipes. American Journal of Applied Sciences, 13(11), 1330-1341. https://doi.org/10.3844/ajassp.2016.1330.1341

Aversa, R., Petrescu, R. V., Petrescu, F. I., \& Apicella, A. (2016h). Biomimetic and evolutionary design driven innovation in sustainable products development. American Journal of Engineering and Applied Sciences, 9(4). https://doi.org/10.3844/ajeassp.2016.1027.1036

Aversa, R., Petrescu, R. V., Sorrentino, R., Petrescu, F. I., \& Apicella, A. (2016f). Hybrid ceramo-polymeric nanocomposite for biomimetic scaffolds design and preparation. American Journal of Engineering and Applied Sciences, 9(4). https://doi.org/10.3844/ajeassp.2016.1096.1105

Aversa, R., Petrescu, RV., Apicella, A., \& Petrescu, FIT. (2017c). Nano-diamond hybrid materials for structural biomedical application. American Journal of Biochemistry and Biotechnology, 13(1), 34-41. https://doi.org/10.3844/ajbbsp.2017.34.41

Aversa, R., Tamburrino, F., Petrescu, R. V., Petrescu, F. I., Artur, M., Chen, G., \& Apicella, A. (2016d). Biomechanically inspired shape memory effect machines driven by muscle like acting NiTi alloys. American Journal of Applied Sciences, 13, 1264-1271. https://doi.org/10.3844/ajassp.2016.1264.1271

Aversa, R., Virgil Petrescu, R. V., Apicella, A., \& Tiberiu Petrescu, F. I. (2019). A nanodiamond for structural biomimetic scaffolds. Engineering Review: Međunarodni časopis namijenjen publiciranju originalnih istraživanja s aspekta analize konstrukcija, materijala i novih tehnologija u području strojarstva, brodogradnje, temeljnih tehničkih znanosti, elektrotehnike, računarstva i Građevinarstva, 39(1), 81-89. https://doi.org/10.30765/er.39.1.9

Beaupre, G. S., \& Hayes, W. C. (1985). Finite element analysis of a three-dimensional open-celled model for trabecular bone. https://doi.org/10.1115/1.3138550

Bonfield, W., Grynpas, M. D., Tully, A. E., Bowman, J., \& Abram, J. (1981). Hydroxyapatite reinforced polyethylene-a mechanically compatible implant material for bone replacement. Biomaterials, 2(3), $185-186$. https://doi.org/10.1016/0142-9612(81)90050-8

Burstein, A. H., Reilly, D. T., \& Martens, M. (1976). Aging of bone tissue: mechanical properties. The Journal of bone and joint surgery. American Volume, 58(1), 82-86. https://doi.org/10.2106/00004623-197658010-00015
Cameron, H. U. (1986). Six-year results with a microporous-coated metal hip prosthesis. Clinical Orthopaedics and Related Research, (208), 81-83. https://doi.org/10.1097/00003086-198607000-00018

Carter, D. R., \& Hayes, W. C. (1977). The compressive behavior of bone as a two-phase porous structure. Journal of Bone Joint Surgery, 59, 954-962. https://doi.org/10.2106/00004623-197759070-00021

Čepelak, I., Dodig, S., \& Čulić, O. (2013). Magnesium-more than a common cation. Rad Hrvatske akademije znanosti i umjetnosti. Medicinske Znanosti, 517(39). file:///C:/Users/PC/Downloads/CEPELAK_DODIG_ CULIC.pdf

Chen, Q., Zhu, C., \& Thouas, G. A. (2012). Progress and challenges in biomaterials used for bone tissue engineering: bioactive glasses and elastomeric composites. Progress in Biomaterials, 1(1), 1-22. https://doi.org/10.1186/2194-0517-1-2

Cormack, A. N., \& Tilocca, A. (2012). Structure and biological activity of glasses and ceramics. Philosophical Transactions of the Royal Society A: Mathematical, Physical and Engineering Sciences, 370(1963), 1271-1280. https://doi.org/10.1098/rsta.2011.0371

Dalstra, M., Huiskes, R., Odgaard, A. V., \& Van Erning, L. (1993). Mechanical and textural properties of pelvic trabecular bone. Journal of Biomechanics, 26(4-5), 523-535. https://doi.org/10.1016/0021-9290(93)90014-6

Davide, A., Raffaella, A., Marco, T., Michele, S., Syed, J., Massimo, M., ... \& Antonio, A. (2015). Direct restoration modalities of fractured central maxillary incisors: A multi-levels validated finite elements analysis with in vivo strain measurements. Dental Materials, 31(12), e289-e305.

https://doi.org/10.1016/j.dental.2015.09.016

Davis, P. A., Huang, S. J., Nicolais, L. U. I. G. I., \& Ambrosio, L. U. I. G. I. (1991). Modified PHEMA hydrogels. High performance biomaterials. Lancaster, PA, USA: Technonic, 343-68. https://doi.org/10.1201/9780203752029-22

Duan, Y., Zhang, H., Sfarra, S., Avdelidis, N. P., Loutas, T. H., Sotiriadis, G., ... \& Maldague, X. P. (2019). On the use of infrared thermography and acoustoultrasonics NDT techniques for ceramic-coated sandwich structures. Energies, 12(13), 2537. https://doi.org/10.3390/en12132537

Filmon, R., Grizon, F., Basle, M. F., \& Chappard, D. (2002). Effects of negatively charged groups (carboxymethyl) on the calcification of poly (2hydroxyethyl methacrylate). Biomaterials, 23(14), 3053-3059. https://doi.org/10.1016/S0142-9612(02)00069-8

Frost, H. M. (1990). Structural adaptations to mechanical usage (SATMU):(2). Redefining Wolff's law: The remodeling problem. Anatomical Record. https://doi.org/10.1002/ar.1092260403 
Frost, H. M. (1994). Wolff's Law and bone's structural adaptations to mechanical usage: an overview for clinicians. The Angle Orthodontist, 64(3), 175-188.

Frost, H. M. (2004). A 2003 update of bone physiology and Wolff's Law for clinicians. The Angle Orthodontist, 74, 3-15. https://pubmed.ncbi.nlm.nih.gov/15038485/

Frost, H. M. (1964). Mathematical Elements of Lamellab Bone Remodeling. Plastic and Reconstructive Surgery, 34(3), 315.

Gorustovich, A. A., Roether, J. A., \& Boccaccini, A. R. (2010). Effect of bioactive glasses on angiogenesis: a review of in vitro and in vivo evidences. Tissue Engineering Part B: Reviews, 16(2), 199-207. https://doi.org/10.1089/ten.teb.2009.0416

Gottesman, T., \& Hashin, Z. (1980). Analysis of viscoelastic behaviour of bones on the basis of microstructure. Journal of Biomechanics, 13(2), 89-96. https://doi.org/10.1016/0021-9290(80)90182-7

Gramanzini, M., Gargiulo, S., Zarone, F., Megna, R., Apicella, A., Aversa, R., ... \& Brunetti, A. (2016). Combined microcomputed tomography, biomechanical and histomorphometric analysis of the peri-implant bone: a pilot study in minipig model. Dental Materials, 32(6), 794-806. https://doi.org/10.1016/j.dental.2016.03.025

Halpin, J. C., \& Kardos, J. L. (1976). The Halpin-Tsai equations: a review. Polymer Engineering and Science, 16, 344-352. https://doi.org/10.1002/pen.760160512

Heinemann, S., Heinemann, C., Wenisch, S., Alt, V., Worch, H., \& Hanke, T. (2013). Calcium phosphate phases integrated in silica/collagen nanocomposite xerogels enhance the bioactivity and ultimately manipulate the osteoblast/osteoclast ratio in a human co-culture model. Acta Biomaterialia, 9(1), 4878-4888. https://doi.org/10.1016/j.actbio.2012.10.010

Hench, L. L. (1993). An introduction to bioceramics (Vol. 1). World Scientific. https://doi.org/10.1142/9789814317351_0001

Hench, L. L., \& Polak, J. M. (2002). Third-generation biomedical materials. Science, 295(5557), 1014-1017. https://doi.org/10.1126/science.1067404

Hench, L. L., \& Thompson, I. (2010). Twenty-first century challenges for biomaterials. Journal of the Royal Society Interface, 7(suppl_4), S379-S391. https://doi.org/10.1098/rsif.2010.0151.focus

Hoppe, A., Güldal, N. S., \& Boccaccini, A. R. (2011). A review of the biological response to ionic dissolution products from bioactive glasses and glass-ceramics. Biomaterials, 32(11), 2757-2774. https://doi.org/10.1016/j.biomaterials.2011.01.004

Huiskes, R., Weinans, H. H. J. G., Grootenboer, H. J., Dalstra, M., Fudala, B., \& Slooff, T. J. (1987). Adaptive bone-remodeling theory applied to prosthetic-design analysis. Journal of Biomechanics, 20(11-12), 1135-1150. https://doi.org/10.1016/0021-9290(87)90030-3
Hutmacher, D. W. (2000). Scaffolds in tissue engineering bone and cartilage. Biomaterials, 21(24), 2529-2543. https://doi.org/10.1016/S0142-9612(00)00121-6

Jones, J., \& Clare, A. (2012). Bio-glasses: an introduction. John Wiley \& Sons. ISBN-10: 1118346467.

Julien, M., Magne, D., Masson, M., Rolli-Derkinderen, M., Chassande, O., Cario-Toumaniantz, C., ... \& Guicheux, J. (2007). Phosphate stimulates matrix Gla protein expression in chondrocytes through the extracellular signal regulated kinase signaling pathway. Endocrinology, 148(2), 530-537. https://doi.org/10.1210/en.2006-0763

Kabra, B. G., Gehrke, S. H., Hwang, S. T., \& Ritschel, W. A. (1991). Modification of the dynamic swelling behavior of poly (2-hydroxyethyl methacrylate) in water. Journal of Applied Polymer Science, 42(9), 2409-2416. https://doi.org/10.1002/app.1991.070420906

Karageorgiou, V., \& Kaplan, D. (2005). Porosity of 3D biomaterial scaffolds and osteogenesis. Biomaterials, 26(27), 5474-5491. https://doi.org/10.1016/j.biomaterials.2005.02.002

Kim, H. W., Knowles, J. C., \& Kim, H. E. (2004). Development of hydroxyapatite bone scaffold for controlled drug release via poly ( $\epsilon$-caprolactone) and hydroxyapatite hybrid coatings. Journal of Biomedical Materials Research Part B: Applied Biomaterials: An Official Journal of the Society for Biomaterials, The Japanese Society for Biomaterials and The Australian Society for Biomaterials and the Korean Society for Biomaterials, 70(2), 240-249. https://pubmed.ncbi.nlm.nih.gov/15264306/

Kumar, A., Rathi, A., Singh, J., \& Sharma, N. K. (2016). Studies on titanium hip joint implants using finite element simulation. In Proceedings of the World Congress on Engineering (Vol. 2).

https://www.semanticscholar.org/paper/Studies-onTitanium-Hip-Joint-Implants-using-Finite-KumarRathi/e7a66aa6b34a3a796b973343ee3f4a6ec22f998d

Kummer, B. (1986). Biomechanical principles of the statics of the hip joint. critical appraisal of a new theory. Zeitschrift fur Orthopadie und ihre Grenzgebiete, 124(2), 179-187. https://doi.org/10.1055/s-2008-1044544

Mano, J. F., Sousa, R. A., Boesel, L. F., Neves, N. M., \& Reis, R. L. (2004). Bioinert, biodegradable and injectable polymeric matrix composites for hard tissue replacement: state of the art and recent developments. Composites Science and Technology, 64(6), 789-817. https://doi.org/10.1016/j.compscitech.2003.09.001

Masteller, A., Sankar, S., Kim, H. B., Ding, K., Liu, X., \& All, A. H. (2020). Recent Developments in Prosthesis Sensors, Texture Recognition, and Sensory Stimulation for Upper Limb Prostheses. Annals of Biomedical Engineering, 1-18. https://doi.org/10.1007/s10439-020-02678-8 
Mazaheri, M., Hassani, K., Karimi, A., \& Izadi, F. (2016). Finite Element Study of Composite Materials as an Alternative for Metal Hip Prothesis Using Variable Load. Materials Focus, 5(5), 430-435. https://doi.org/10.1166/mat.2016.1342

Mirsayar, M. M., \& Park, P. (2016). Modified maximum tangential stress criterion for fracture behavior of zirconia/veneer interfaces. Journal of the Mechanical Behavior of Biomedical Materials, 59, 236-240. https://doi.org/10.1016/j.jmbbm.2015.11.037

Mirsayar, M. M., Joneidi, V. A., Petrescu, R. V. V., Petrescu, F. I. T., \& Berto, F. (2017). Extended MTSN criterion for fracture analysis of soda lime glass. Engineering Fracture Mechanics, 178, 50-59. https://doi.org/10.1016/j.engfracmech.2017.04.018

Montheard, J. P., Chatzopoulos, M., \& Chappard, D. (1992). 2-hydroxyethyl methacrylate (HEMA): chemical properties and applications in biomedical fields. Journal of Macromolecular Science, Part C: Polymer Reviews, 32(1), 1-34. https://doi.org/10.1080/15321799208018377

Morales-Hernandez, D. G., Genetos, D. C., Working, D. M., Murphy, K. C., \& Leach, J. K. (2012). Ceramic identity contributes to mechanical properties and osteoblast behavior on macroporous composite scaffolds. Journal of Functional Biomaterials, 3(2), 382-397. https://doi.org/10.3390/jfb3020382

Mourino, V., Cattalini, J. P., \& Boccaccini, A. R. (2012). Metallic ions as therapeutic agents in tissue engineering scaffolds: an overview of their biological applications and strategies for new developments. Journal of the Royal Society Interface, 9(68), 401-419. https://doi.org/10.1098/rsif.2011.0611

Mullender, M. G., \& Huiskes, R. (1995). Proposal for the regulatory mechanism of Wolff's law. Journal of Orthopaedic Research, 13(4), 503-512. https://doi.org/10.1002/jor.1100130405

Oh, I., \& Harris, W. H. (1978). Proximal strain distribution in the loaded femur. An in vitro comparison of the distributions in the intact femur and after insertion of different hip-replacement femoral components. The Journal of bone and joint surgery. American Volume, 60(1), 75-85. https://pubmed.ncbi.nlm.nih.gov/624762/

Peluso, G., Petillo, O., Anderson, J. M., Ambrosio, L., Nicolais, L., Melone, M. A. B., ... \& Huang, S. J. (1997). The differential effects of poly (2-hydroxyethyl methacrylate) and poly (2-hydroxyethyl methacrylate)/poly (caprolactone) polymers on cell proliferation and collagen synthesis by human lung fibroblasts. Journal of Biomedical Materials Research: An Official Journal of the Society for Biomaterials and The Japanese Society for Biomaterials, 34(3), 327-336. https://doi.org/10.1002/(SICI)10974636(19970305)34:3<327::AID-JBM7>3.0.CO;2-M
Perillo, L., Sorrentino, R., Apicella, D., Quaranta, A., Gherlone, E., Zarone, F., ... \& Apicella, A. (2010). Nonlinear visco-elastic finite element analysis of porcelain veneers: a submodelling approach to strain and stress distributions in adhesive and resin cement. Journal of Adhesive Dentistry, 12(5), 403.

Petrescu, F. I. T. (2019). About the nuclear particles' structure and dimensions. Computational Particle Mechanics, 6(2), 191-194. https://doi.org/10.1007/s40571-018-0206-7

Petrescu, F. I. T., Apicella, A., Aversa, R., Petrescu, R. V., Calautit, J. K., Mirsayar, M. M., \& Riccio, A. (2016a). Something about the mechanical moment of inertia. American Journal Applied Science, 13(11), 1085-1090. https://doi.org/10.3844/ajassp.2016.1085.1090

Petrescu, R. V., Aversa, R., Apicella, A., Li, S., Chen, G., \& Petrescu, F. I. (2016b). Something about electron dimension. American Journal of Applied Sciences, 13(11), 1272-1276. https://doi.org/10.3844/ajassp.2016.1272.1276

Petrescu, R. V., Aversa, R., Apicella, A., Berto, F., Li, S., \& Petrescu, F. I. (2016c). Ecosphere protection through green energy. American Journal of Applied Sciences, 13(10), 1027-1032. https://doi.org/10.3844/ajassp.2016.1027.1032

Petrescu, F. I., Apicella, A., Petrescu, R. V., Kozaitis, S., Bucinell, R., Aversa, R., \& Abu-Lebdeh, T. (2016d). Environmental protection through nuclear energy. American Journal of Applied Sciences, 13, 941-946. https://doi.org/10.3844/ajassp.2016.941.946

Petrescu, R. V., Aversa, R., Apicella, A., \& Petrescu, F. I. (2016e). Future medicine services robotics. American Journal of Engineering and Applied Sciences, 9(4), 1062-1087. https://doi.org/10.3844/ajeassp.2016.1062.1087

Petrescu, F. I. T., Petrescu, R. V., \& Mirsayar, M. (2017). The computer algorithm for machine equations of classical distribution. Journal of Materials and Engineering Structures, 4(4), 193-209. http://revue.ummto.dz/index.php/JMES/article/view/ 1590

Petrescu, F. I. T., Petrescu, R. V., \& Mirsayar, M. M., (2018). Inverse kinematics to a stewart platform. Journal of Materials and Engineering Structures, 5(2), 111-122. https://core.ac.uk/download/pdf/229491873.pdf

Petrescu, F. I., \& Petrescu, R. V. (2019). The Human Body's Hydraulics. Independent Journal of Management \& Production (IJM\&P), 10(6). https://doi.org/10.14807/ijmp.v10i6.932

Petrescu, F. I., \& Petrescu, R. V. (2020). Some Aspects Related to the Human Body Plant. Independent Journal of Management \& Production (IJM\&P), 11(1). https://doi.org/10.14807/ijmp.v11i1.944 
Petrescu, F. L., Buzea, E., Nănuţ, L., Neacşa, M., \& Nan, C. (2015). The role of antioxidants in slowing aging of skin in a human, Analele Univers. Craiova Biologie Horticultura Tehn. Prel. Prod. Agr. Ing. Med, 20(1), 567-574.

Petrescu, R. V., Aversa, R., Apicella, A., \& Petrescu, F. I. (2019a). Some Aspects of the Human Body's Hydraulics. OnLine Journal of Biological Sciences, 19(3), 159-185. https://doi.org/10.3844/ojbsci.2019.159.185

Petrescu, R. V. V., Aversa, R., Apicella, A., \& Petrescu, F. I. T., (2019b). Biologically structured materials. Independent Journal of Management and Production, 10(8), 1772-1818. https://doi.org/10.14807/ijmp.v10i8.1084

Petrescu, R. V., Aversa, R., Apicella, A., \& Petrescu, F. I. (2020). Presents Some Biologically Structured Materials. OnLine Journal of Biological Sciences, 20(1), 8-36. https://doi.org/10.3844/ojbsci.2020.8.36

Prashantha, K., Pai, K. V. K., Sherigara, B. S., \& Prasannakumar, S. (2001). Interpenetrating polymer networks based on polyol modified castor oil polyurethane and poly (2-hydroxyethylmethacrylate): Synthesis, chemical, mechanical and thermal properties. Bulletin of Materials Science, 24(5), 535-538. https://doi.org/10.1007/BF02706727

Reilly, D. T., \& Burstein, A. H. (1974). The mechanical properties of cortical bone. JBJS, 56(5), 1001-1022. https://doi.org/10.2106/00004623-197456050-00012

Reilly, D. T., \& Burstein, A. H. (1975). The elastic and ultimate properties of compact bone tissue. Journal of Biomechanics, 8(6), 393-405. https://doi.org/10.1016/0021-9290(75)90075-5

Rohlmann, A., Mössner, U., Bergmann, G., \& Kölbel, R. (1982). Finite-element-analysis and experimental investigation of stresses in a femur. Journal of Biomedical Engineering, 4(3), 241-246. https://doi.org/10.1016/0141-5425(82)90009-7

Schiraldi, C., D’Agostino, A., Oliva, A., Flamma, F., De Rosa, A., Apicella, A., ... \& De Rosa, M. (2004). Development of hybrid materials based on hydroxyethylmethacrylate as supports for improving cell adhesion and proliferation. Biomaterials, 25(17), 3645-3653. https://doi.org/10.1016/j.biomaterials.2003.10.059
Schwartz-Dabney, C. A., \& Dechow, P. C. (2003). Variations in cortical material properties throughout the human dentate mandible. American Journal of Physical Anthropology: The Official Publication of the American Association of Physical Anthropologists, 120(3), 252-277. https://doi.org/10.1002/ajpa.10121

Sorrentino, R., Apicella, D., Riccio, C., Gherlone, E., Zarone, F., Aversa, R., ... \& Apicella, A. (2009). Nonlinear visco-elastic finite element analysis of different porcelain veneers configuration. Journal of Biomedical Materials Research Part B: Applied Biomaterials: An Official Journal of the Society for Biomaterials, the Japanese Society for Biomaterials, and the Australian Society for Biomaterials and the Korean Society for Biomaterials, 91(2), 727-736. https://doi.org/10.1002/jbm.b.31449

Sorrentino, R., Aversa, R., Ferro, V., Auriemma, T., Zarone, F., Ferrari, M., \& Apicella, A. (2007). Threedimensional finite element analysis of strain and stress distributions in endodontically treated maxillary central incisors restored with diferent post, core and crown materials. Dental Materials, 23(8), 983-993. https://doi.org/10.1016/j.dental.2006.08.006

Taylor, D., Hazenberg, J. G., \& Lee, T. C. (2007). Living with cracks: damage and repair in human bone. Nature materials, 6(4), 263-268. https://doi.org/10.1038/nmat1866

Töyräs, J., Lyyra-Laitinen, T., Niinimäki, M., Lindgren, R., Nieminen, M. T., Kiviranta, I., \& Jurvelin, J. S. (2001). Estimation of the Young's modulus of articular cartilage using an arthroscopic indentation instrument and ultrasonic measurement of tissue thickness. Journal of Biomechanics, 34(2), 251-256. https://doi.org/10.1016/S0021-9290(00)00189-5

Weinans, H., Huiskes, R., \& Grootenboer, H. J. (1992). The behavior of adaptive bone-remodeling simulation models. Journal of Biomechanics, 25(12), 1425-1441. https://doi.org/10.1016/0021-9290(92)90056-7

Wolff, J. (1892). Das gesetz der transformation der knochen. A Hirshwald, 1, 1-152. https://www.worldcat.org/title/gesetz-dertransformation-der-knochen/oclc/41446398 